\title{
El gran cementerio. Hacia una nueva interpretación de la Valencina calcolítica
}

\section{The great cemetery. Towards a new interpretation of Chalcolithic Valencina}

José Luis Escacena Carrasco ${ }^{1}$

Isabel Rondán Sevilla ${ }^{2}$

Miguel Flores Delgado ${ }^{3}$

Recibido: 16-01-2018

Aceptado: 24-09-2018

\section{Resumen}

El yacimiento calcolítico de Valencina tiene unas características tan peculiares que difícilmente puede ser interpretado como un poblado más de los conocidos en el Sur de la península ibérica. Su enorme extensión, su registro arqueológico y la falta de estructuras claramente domésticas le otorgan una gran singularidad. Por otra parte, la especial abundancia de registro funerario contrasta con la ausencia del mismo en muchos kilómetros a la redonda, donde se conocen otros yacimientos. Estos rasgos nos permiten proponer que Valencina fue básicamente una necrópolis comarcal con sus posibles servicios anejos, y no un asentamiento propiamente dicho.

Palabras clave: Valencina, Calcolítico, asentamiento, necrópolis, ídolos, tumbas.

\begin{abstract}
The chalcolithic site of Valencina has some singular characteristics that it can hardly be interpreted as one more known settlement in the South of the Iberian peninsula. Its huge extension, its archeological record and the lack of clearly domestic structures give it a great singularity. On the other hand, the special abundance of the funerary documentation contrasts with the absence of the same in many kilometers around, where other sites are known. These features allow us to propose that Valencina was basically a comarcal necropolis with its possible ancillary services, and not a genuine settlement.
\end{abstract}

Keywords: Valencina, Chalcolithic, settlement, necropolis, idols, tombs.

\section{INTRODUCCIÓN}

Desde que se descubriera en las cercanías de Sevilla el megalito conocido como Cueva de la Pastora, las evidencias de un gran yacimiento calcolítico cercano a la antigua desembocadura del Guadalquivir no han hecho más que aumentar. El registro de materiales arqueológicos en este sitio ha ido dando a conocer un yacimiento que ha crecido en extensión conforme se hacían nuevas investigaciones o se realizaban campañas preventivas de salvamento patrimonial. Conocemos el tholos de La Pastora desde 1860, año en el que se accedió casualmente a su interior. Entonces el yacimiento ocupaba sólo lo que aquel hipogeo; pero hoy, más de siglo y medio después, las

1 Departamento de Prehistoria y Arqueología. Facultad de Geografía e Historia. Universidad de Sevilla. C/ Doña María de Padilla s.n. 41004, Sevilla. escacena@us.es. ORCID: http://orcid.org/0000-0003-4935-9308.

2 Arqueóloga. Universidad de Sevilla. isa_rs_arcos@hotmail.com.

3 Universidad de Sevilla. miguel_fd_97@hotmail.com. 
últimas estimaciones elevan su extensión hasta las 450 ha. Tal vez el tamaño actual sea el resultado de desplazamientos en horizontal de su ocupación a lo largo del tiempo en que lo frecuentaron las comunidades locales de la zona, ya que estuvo vigente casi un milenio según los cálculos cronológicos más completos realizados hasta ahora (García Sanjuán et al. 2018). Este rasgo ha motivado su clasificación como megayacimiento al compararlo con otros enclaves de la época (García Sanjuán et al. 2017).

El sitio calcolítico ocupa el punto más alto de la cornisa oriental del Aljarafe, en la margen derecha del Guadalquivir, y se extiende por los términos municipales de Valencina de la Concepción, Castilleja de Guzmán y Camas, aunque en la historiografía se le conoce casi siempre sólo como "Valencina". Su enorme superficie, aún en crecimiento conforme se intensifica la investigación, no fue percibida hasta las últimas décadas del siglo XX, cuando recibieron un gran impulso los trabajos de campo en diversos sectores del yacimiento, primero desde el Museo Arqueológico de Sevilla y más tarde bajo la tutela de la Consejería de Cultura de la Junta de Andalucía. Es sorprendente desde luego el considerable tamaño del enclave, pero no lo son menos otros rasgos que vamos a analizar y que permiten construir una nueva hipótesis con la que profundizar en su comprensión. Se trata, por ejemplo, de la notable escasez de estructuras que puedan considerarse realmente cabañas al estilo de las encontradas en otros yacimientos calcolíticos, por ejemplo en Millares (Almagro y Arribas 1963: 31-46; Arribas et al. 1983: 146-147). También es destacable, pensando sobre todo en su envergadura, la casi nula representación de utensilios propios del cultivo y procesado de cereales, como serían los denticulados líticos para las hoces (Murillo 2013: 472-479) ${ }^{4}$ o los molinos de vaivén. Algunas de estas características han sido advertidas ya por la investigación (García Sanjuán 2013: 33$35)$, lo que ha permitido insistir en el carácter peculiar de Valencina como posible lugar de agregación social más que como un simple poblado. A esto se añade, en la misma línea argumental, que la fabricación de útiles de sílex está prácticamente descartada en el yacimiento. De hecho, son escasísimos los núcleos de extracción y los restos de talla, dos elementos indicativos de una producción local (Murillo 2013: 471 y 474). En cualquier caso, el yacimiento de Valencina ha sido interpretado también como capital de un estado prístino de Andalucía occidental, lectura especialmente querida por los prehistoriadores marxistas que han trabajado en el tema (Nocete 2001).

4 En el trabajo de T. Murillo citado se recogen diversos denticulados, no todos identificados por la autora como piezas para hoces. Sí lo es con claridad un ejemplar hallado en el hipogeo funerario de Montelirio (García Sanjuán et al. 2016: 223).
La sospecha de que Valencina no fue un mero asentamiento al estilo de Millares o de Zambujal es un tema presente en la investigación. Pero es necesario dar un nuevo paso hacia su interpretación concreta más allá de que se considere genéricamente un importante sitio de reuniones colectivas. Un santuario es un espacio de agregación social, pero también lo son los puntos de mercado o intercambio, los puertos, los estadios deportivos y otros muchos lugares; lo son de hecho hasta los propios poblados, papel asignado tradicionalmente a Valencina. Por eso hace falta proponer para este enclave una hipótesis de trabajo que permita un nivel de resolución mucho más fino. Para esta labor se requiere conocer el registro completo de lo excavado hasta ahora, cuestión nada fácil porque muchas intervenciones arqueológicas mantienen inéditos sus resultados. Recientemente se ha hecho un gran esfuerzo en aliviar esta situación, plasmado en dos obras voluminosas generadas con motivo del 150 aniversario del descubrimiento de La Pastora (García Sanjuán 2013) y de la excavación del sector de Montelirio (Fernández Flores et al. 2016). Pero carecemos aún de una publicación extensa que proporcione una visión global del yacimiento, una obra que permita situar cada cosa en su sitio y que facilite la interpretación del conjunto. Citaremos líneas abajo algunos artículos que intentan abordar esta síntesis ofreciendo a la vez un análisis detallado de algunos de los caracteres básicos del yacimiento, pero la principal monografía permanece aún inédita, por lo que es imposible contar con ella para la presente propuesta ${ }^{5}$.

Para desarrollar nuestra interpretación es fundamental el análisis de la ocupación calcolítica del territorio donde se inserta Valencina. Muchos estudios llevados a cabo sobre el yacimiento olvidan este aspecto, centrándose sólo en sus rasgos internos. Otras veces la investigación ha relacionado el lugar con áreas mucho más lejanas que las propiamente comarcales, sobre todo al estudiar los materiales exóticos con que fueron elaborados algunos ajuares funerarios. Un ejemplo paradigmático es el que tiene que ver con la identificación del marfil y de sus regiones de procedencia (Schuhmacher 2016); pero otros casos se refieren al uso del cinabrio como colorante simbólico (Emslie et al. 2016) o de ciertas rocas de lejano origen (Odriozola 2016). Por el contrario, nuestro interés se centrará ahora en el análisis del territorio inmediato, porque se conocen ya en este ámbito muchos asentamientos de diverso tamaño que, excavados o no, completan notablemente la información necesaria para comprender el papel jugado por la propia Valencina en relación con

5 Se trata de la Tesis Doctoral de J.C. Mejías García, defendida en la Universidad de Sevilla en 2017 con el título Formaciones sociales del III milenio A.N.E. en Valencina. 
todos ellos. Como veremos, este examen puede proporcionar claves importantes para concretar la función que buscamos para este yacimiento, y que fue su razón de ser para la gente que poco a poco lo creó. En este sentido, el contexto de rango medio de Valencina, que va más allá del propio sitio pero que no llega a tener carácter regional, puede entenderse como el área principal de donde se extrajeron los productos agropecuarios básicos de la población allí sepultada, aunque otros recursos referidos a los sectores secundario y terciario pudieran provenir también de territorios mucho más distantes.

Los estudios del entorno inmediato -el círculo que pretendemos definir- tampoco presentan un conocimiento sistemático de la situación por parte de planes con cierta envergadura y continuidad, si exceptuamos el Proyecto Estuario, llevado a cabo entre 1993 y 1998 en el sector de la paleodesembocadura bética (Escacena e Izquierdo 1999). Pero las múltiples atenciones que este territorio ha recibido para salvaguardar su rico patrimonio arqueológico han proporcionado ya una información suficiente para nuestra hipótesis, aunque esos datos se encuentren dispersos en múltiples actuaciones particulares, memorias de excavaciones preventivas, proyectos arqueológicos dedicados a otras cronologías, cartas arqueológicas, etc. Sin duda, contar con toda esta información facilita sobremanera una nueva lectura para la Valencina calcolítica.

\section{Planteamiento de la Hipótesis}

La fuerte atracción que ejerció Valencina como sitio principal de la zona puede explicar muchos de los rasgos observados para la Edad del Cobre en el territorio circundante, en especial la ausencia de registro funerario y de las figurillas rituales comúnmente conocidas como "ídolos". En cualquiera de sus versiones, tanto las sepulturas como estos iconos sólo aparecen en Valencina, mientras que conocemos en cambio diversos asentamientos claramente identificables como meros hábitats. Estos rasgos muestran un fuerte contraste entre Valencina y "sus" territorios circundantes, pero ese comportamiento diferente ha carecido hasta ahora de explicación por el simple hecho de no haberse percibido. Culpa de ello ha sido la focalización de los esfuerzos y de los recursos sólo en ese gran yacimiento, seguramente como consecuencia en parte de la espectacularidad de sus monumentos megalíticos y de la riqueza de sus ajuares funerarios. Pero es también responsable de este estado de cosas la fuerte inercia de la investigación, que siempre buscó en el yacimiento, sólo y afanosamente, un poblado digno de tan enorme y rica necrópolis.

Esta realidad de los hechos arqueológicos está por plantear abiertamente en la investigación del Calcolítico comarcal. Se han detectado numerosos asentamientos de este periodo entre Alcalá del Río y
Doñana, límites norte y sur respectivamente del estuario bético actual. Pero no deja de extrañar que apenas se hayan constatado enterramientos en este ámbito fluvial. Lo mismo ocurre si se echa una ojeada hacia el norte y hacia el oeste. Mientras tanto, en Valencina las sepulturas suministran el grueso de la información, por no decir casi su totalidad. Fuera de este enclave, la falta de tumbas en la zona es, por lo demás, un rasgo que afecta tanto a los posibles hallazgos accidentales como a las búsquedas generales emprendidas en el territorio mediante prospecciones sistemáticas exhaustivas. Esto sugiere que no estamos ante una simple consecuencia del azar, y obliga a la vez a ofrecer una explicación del fenómeno.

Por esta razón proponemos que este enclave concentraba todas las tumbas de las comunidades humanas del entorno en un radio de unos treinta kilómetros a la redonda. En principio, el territorio que tenía a Valencina como necrópolis compartida parece extenderse por el paleoestuario del Guadalquivir, al menos desde Alcalá del Río hasta que el paisaje del Aljarafe va siendo sustituido hacia el sur por el flanco oeste de la comarca de Las Marismas. Hacia poniente pudo llegar al menos hasta el Guadiamar. Los contornos parecen estar más claros en el lado oriental, en coincidencia con la orilla izquierda de la ribera bética. De hecho, el asentamiento de Gandul pudo representar otro de esos núcleos funerarios comarcales que, en paralelo con Valencina, aglutinaba la población difunta de la mitad sur de Los Alcores. Sin embargo, no resultaría extraño que futuras investigaciones pudiesen ampliar el área de influencia de Valencina, incluyendo hacia el noroeste la zona minera de Aznalcóllar y hacia el oeste-suroeste parte de la comarca onubense del Condado, espacios que ofrecen más dudas para esta versión primera de nuestra hipótesis. Esto explicaría la ausencia de megalitos en dirección occidental hasta el término municipal de Villarrasa, ya en la provincia de Huelva. Estudios recientes indican precisamente que el cobre documentado en Valencina procedía de al menos treinta kilómetros de distancia, en concreto de la Faja Pirítica del Suroeste que comienza a aflorar en Aznalcóllar, lo que permite unir aquí ciertos datos económicos comarcales con la información funeraria.

La ausencia de enterramientos en todo este amplio territorio, exceptuada lógicamente Valencina, se explicaría, pues, por ser este gran núcleo el cementerio comunitario de todos los asentamientos de un ámbito geográfico con conciencia de unidad grupal. Por otra parte, toda esta comarca, en la que conocemos bastantes enclaves calcolíticos, carece también de "ídolos", que en cambio están constatados abundantemente en Valencina. Este rasgo puede explicarse precisamente con la misma hipótesis, ya que esas figurillas constituyen claros testimonios de prácticas funerarias.

El papel de Valencina como necrópolis mancomunada, a su vez constituida por agrupaciones de tumbas 
correspondientes a clanes y/o a grupos locales con puntos de residencia distintos, pudo perpetuarse al menos hasta el incremento del cambio cultural que supuso la fase final del fenómeno campaniforme, cuando el mundo de la Edad del Cobre muestra claras evidencias de descomposición. Por tanto, la presente hipótesis podría resistir el hallazgo de algunas sepulturas en esta zona con fronteras aún imprecisas, sobre todo si tales tumbas corresponden a un momento muy tardío del Calcolítico.

Verificar la hipótesis recién expuesta requiere que se cumplan al menos dos condiciones, que se convierten de manera automática en predicciones explícitas de lo que debería mostrar el registro arqueológico presente y futuro. Por una parte, no tendrían que aparecer enterramientos en los enclaves cercanos a Valencina, al menos en los pertenecientes a la fase en que este sitio ejerció fuertemente su atracción simbólica sobre la paleodesembocadura del Guadalquivir y comarcas adyacentes, es decir, básicamente en el III milenio cal $\mathrm{BC}$, cuando todavía no se había asistido a los inicios de la descomposición social y política que trajo consigo el colapso epicalcolítico. Por otro lado, y en segundo lugar, debería constatarse de alguna forma una fuerte vinculación de los "ídolos" con el mundo del más allá, ya que estas piezas también muestran una dispersión similar a la documentada para las tumbas: están ausentes de todo el territorio circundante mientras aparecen sólo en Valencina. Analizaremos a continuación ambos requisitos, cuya falsación popperiana nos per- mitirá afirmar que, según los datos hasta ahora controlados, la Valencina de la Edad del Cobre no pudo ser otra cosa que un cementerio comunitario de ámbito comarcal.

\section{Algunas Cuestiones de método}

La base metodológica para delimitar el mapa donde Valencina ejerció su dominio como necrópolis se sustenta, primero, en identificar otros focos periféricos que cuenten también con registro funerario. Este hecho manifestaría que esos otros sitios escapaban de la fuerza centrípeta ejercida por Valencina, desvelando espacios mortuorios locales independientes y distintos del que pretendemos perfilar. En segundo lugar emprenderemos un recorrido por el área interna delimitada por esas otras necrópolis exteriores, ahora con el fin de detectar asentamientos calcolíticos y verificar que en ellos no existe registro funerario. Así, el patrón teórico quedaría definido por un mosaico en panal donde las necrópolis actuarían como núcleos simbólicos vertebradores del territorio (fig. 1).

Para este doble cometido usaremos dos clases de marcadores arqueológicos, cuya ubicación coincidente en ciertos lugares revela su complementariedad. El mejor identificador es, evidentemente, la presencia en sí de tumbas en cualquiera de sus manifestaciones calcolíticas conocidas. Para el propósito que lo usamos, este ítem no necesita más justificación, aunque conviene aclarar que daremos por tal sepultura tanto las que

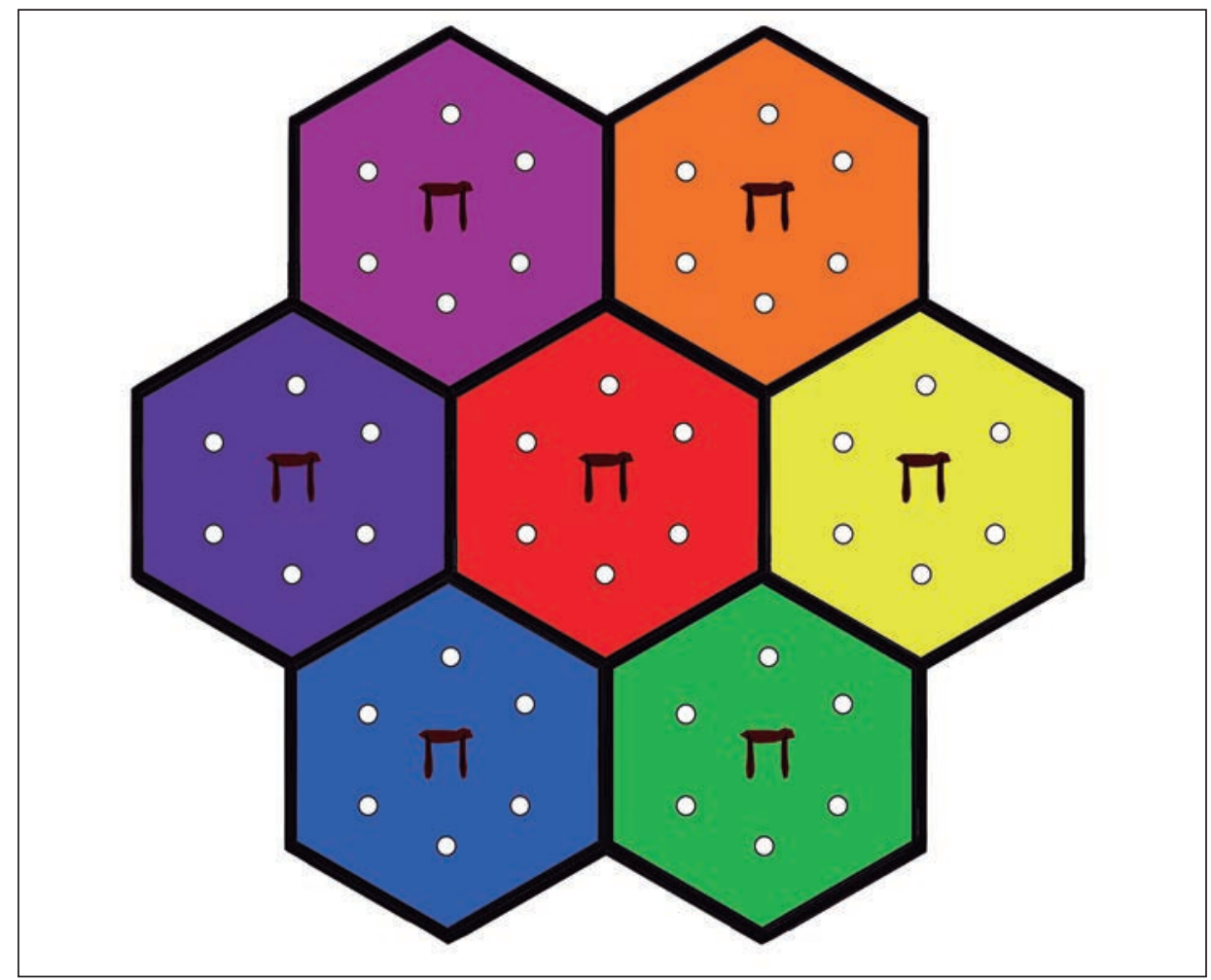

Figura 1. Modelo teórico de la división territorial en distritos funerarios. 
contienen restos humanos en conexión anatómica como los monumentos megalíticos clasificados tradicionalmente como funerarios, aunque las labores arqueológicas llevadas a cabo en ellos no hayan detectado ningún enterramiento. En este caso, la falta de evidencias óseas suele deberse al expolio o a la carencia de investigaciones. El segundo marcador corresponde a la presencia de "ídolos". Aunque éstos han aparecido con mucha frecuencia en sepulturas, nuestra hipótesis requiere afianzar la idea de que no son imágenes de dioses, como su nombre tradicional sugiere, sino expresiones plásticas de duelo. Por ello dedicaremos previamente unas cuantas reflexiones a profundizar en esta idea. Con ello reforzamos además la interpretación de Valencina básicamente como una extensa necrópolis, ya que en este yacimiento aparecen con profusión tales figurillas.

Los argumentos que invalidan a los "ídolos" como representaciones divinas han sido publicados ya por uno de los firmantes (Escacena 2016), por lo que sólo los retomaremos aquí de forma sintética. El problema básico que presentan es que su interpretación clásica nunca ha sido demostrada. La misma María José Almagro (1973), autora del mayor corpus sobre el tema, asumió su identificación con dioses más como presupuesto axiomático que como conclusión. De esta forma, dio por demostrado desde el comienzo de su monografía lo que en realidad debería haber sido la conclusión. Sólo recientemente K. Lillios (2008) ha presentado una idea distinta con un amplio trabajo detrás, concretada en que representaran blasones familiares del difunto y la distancia genealógica entre éste y el fundador clánico. Como dicha propuesta ha sido negada convincentemente por otros autores (García Rivero y O'Brien 2014), no resulta necesario rebatirla. Respecto a que fueran imágenes de entes sagrados, se ha sostenido que aludirían a una diosa ave, ya que algunos ejemplares pueden recordar rapaces nocturnas. Pero su versión antropomorfa muestra a veces el sexo, los cabellos y, en el tipo "placa", posibles vestimentas. En consecuencia, resulta muy difícil aceptar esta popular interpretación como búhos o lechuzas. Se trata sin duda de representaciones humanas en todos los casos, al menos en los que muestran ojos. Argumentaremos, en consecuencia, por qué puede admitirse que estas imágenes se refieren en realidad a los dolientes más cercanos de la persona fallecida, y que expresan el dolor que éstos sintieron por la muerte del ser querido al que despedían en su viaje al más allá.

Un repaso general a su iconografía revela que rara vez explicitan sus atributos sexuales de tipo somático. Sin embargo, los demás rasgos anatómicos (ojos, cejas y pelo) son siempre caracteres antropomorfos. Son culturales en cambio los referidos a la vestimenta, al peinado y al comúnmente conocido como "tatuaje facial". Disponer de ojos, cejas y largas melenas puede sugerir que se trata de simples imágenes humanas, pero estas propiedades podrían también aparecer en figuras de dioses antropomorfos. Lo mismo podemos afirmar de la vestimenta y del tratamiento del cabello. Tales semejanzas, compartidas entre nuestra especie y cualquier ser divino con cuerpo humano, impiden saber, en principio, si aluden a meras personas o a verdaderas entidades sagradas. En consecuencia, la clave para averiguar qué se quiso plasmar en ellas debería proporcionarla el restante elemento cultural casi nunca olvidado en sus rostros: el "tatuaje facial".

Las dos palabras alusivas a este singular rasgo, tan frecuentes en la literatura especializada sobre el Calcolítico ibérico, corresponden a las incisiones que muestran en las mejillas, y cuya interpretación como verdaderos tatuajes tiene detrás menos argumentos que inercia historiográfica. Fueran de piedra, de barro, de hueso o de algún otro material, los "ídolos" conocieron su apogeo en la Edad del Cobre, para desaparecer del registro con el colapso de esta fase a finales del III milenio cal BC. Las incisiones faciales se prolongan a veces casi hasta la nuca, y su simétrico zigzagueo a ambos lados de la cara corresponde tal vez a la esquematización gráfica de una posible realidad más caótica que practicaran los allegados del difunto en su propia cara. Quienes aceptan que estos surcos son tatuajes genuinos suponen que puedan referirse a elementos simbólicos, como agua que fluye (Almagro 1973: 326). Pero los ambientes arqueológicos donde aparecen indican lazos estrechos con rituales funerarios, sobre todo porque son muy escasos en el conjunto de piezas hispanas con contextos conocidos los ejemplares no hallados en sepulturas. Por eso, dichas estrías podrían referirse al luto expresado en los funerales por las personas social y familiarmente más próximas al muerto, que en casos extremos se arañarían el rostro como señal de duelo. Mediante esta expresión de pena se mostraba a la comunidad sentimientos de pesar por la desaparición del ser querido. De esta forma, los objetos tenidos hasta ahora por imágenes de dioses podrían ser simples representaciones humanas transmisoras de sentimientos de luto.

Desgarrarse las mejillas como exteriorización de duelo y desesperación fue una costumbre muy practicada en el mundo antiguo. Su plasmación en objetos materiales se conoce también en ambientes siropalestinos y chipriotas de la Edad del Hierro (Escacena y Gómez Peña 2015). De todas formas, más allá de la aceptación general del nombre no se ha demostrado aún que estas laceraciones aludan a cicatrices, a costurones o a pinturas que la gente llevara en vida por motivos estéticos o étnicos. Esta última idea sí se ha barajado, sobre todo al dar por hecho que los "tatuajes" son lo que encierra literalmente esa palabra. Por lo demás, los rasguños faciales como marcas de ciertas plañideras y de otros asistentes a los funerales disponen de una amplia constatación etnográfica (Frazer 1981: 509-532), y perviven aún en la fiesta chií de la 
Ashura. Se describe bien, por otra parte, en algunos textos de la Biblia hebrea, siempre como manifestación de duelo (1 Reyes 18: 28-29; Levítico 19: 28; 21: 5; Jeremías 16: 6; 47: 5; 48: 37). Algunos textos cananeos del II milenio a.C. que narran la muerte del dios Baal citan el empleo de cuchillos de piedra para autoinfligirse estas ablaciones (Del Olmo 1995: 108 y 195).

Los hasta ahora denominados "ídolos" calcolíticos de la península ibérica muestran muchas veces claros rasguños faciales. Los ejemplares menos complejos, que incluso pueden carecer de ojos y de otros caracteres anatómicos, no olvidan en cambio estas cicatrices, al menos una en cada mejilla, evidenciando que es este rasgo el esencial de su función. En cualquier caso, lo estadísticamente normal es que aparezcan en mayor cantidad, entre dos y diez según el catálogo recogido por M.J. Almagro (1973). Este número no contradice la nueva hipótesis si la acción de arañarse la cara se realizaba una o dos veces. La nueva lectura niega por tanto que estas piezas aludan a divinidades, y propone que podrían referirse tanto a familiares y amigos como a súbditos y/o clientes del difunto. Por otra parte, como en la variedad antropomorfa se explicita en ocasiones el sexo, podemos admitir que personificaban a hombres y a mujeres.

Que estas piezas sean de uso exclusivamente funerario supone una herramienta fundamental con la que trabajar nuestra interpretación de Valencina. De hecho, si no son imágenes de dioses podemos rechazar con más facilidad que ese gran enclave fuera en principio un santuario, sin que ello suponga negarle necesariamente su existencia dentro del enclave o el carácter sagrado de todo el lugar. Son de capital importancia, en consecuencia, dos cuestiones que refuerzan el papel del yacimiento como centro esencialmente funerario: el contexto de las figurillas de este tipo aparecidas en Valencina y su ausencia en muchos kilómetros a la redonda. Como veremos, la primera premisa permite robustecer la asociación entre registro funerario y presencia de "ídolos", insertando el sitio, a pesar de su extraordinario tamaño, en la tónica general que el mundo de la muerte muestra en gran parte del sur hispano durante la Edad del Cobre, donde "ídolos" y tumbas van casi siempre de la mano. La segunda condición permite de nuevo establecer un posible límite para el área de influencia de Valencina, ya que la presencia de estas figurillas lejos de este enclave del Aljarafe permitiría hablar de zonas donde dicho centro no tenía ya poder de atracción funeraria para las comunidades locales.

\section{EN EL EXTRARRADIO}

Más allá de Valencina, el reparto de los indicadores funerarios elegidos en el apartado anterior permite establecer un límite donde este sitio ya no desempeñaba el papel de cementerio de los distintos hábitats. A fin de ordenar la búsqueda de esta frontera lejana, hemos dividido el territorio circundante en ocho sectores radiales a partir de un centro representado por la propia Valencina. De esta forma, la presencia de tumbas o de "ídolos" en cualquiera de los segmentos de círculo resultantes marcará un límite más allá del cual se hace innecesario seguir el examen, ya que ese punto concreto de cada sector demostraría la existencia de otra necrópolis distinta. Comenzaremos el recorrido de esos segmentos de círculo en la parte donde se situaba la cabecera del estuario bético, es decir, en el flanco noreste del área teórica que suponemos tenía a Valencina como recinto funerario. Analizaremos todo ese ámbito geográfico en el sentido de las agujas del reloj, numerando del I al VIII los distintos sectores. Para identificar ese horizonte último es suficiente la localización de un solo enclave funerario en cada sector, aunque la bibliografía ya existente permite aumentar la relación (fig. 2).

En el sector I el límite máximo correspondería a los dólmenes de Las Canteras y Puerto de los Entierros, en la localidad de Guillena (IAPH 2000). Se trata de monumentos megalíticos que, pese a no estar investigados en profundidad, revelan la existencia de un foco de enterramientos ajeno a Valencina. Algo más al este, el sector II cuenta con un enclave donde se han encontrado tanto sepulturas como "ídolos". Se trata de Carmona, yacimiento en el que las inhumaciones y esas figurillas -en este caso un "ídolo" tolva- ocupan una misma estructura funeraria subterránea de tipo "silo" (Conlin 2017: 22-35). Parecida circunstancia podemos observar en el área o sector III, con diversos hipogeos megalíticos a veces parasitados durante el Bronce Antiguo por inhumaciones individuales en fosas (Hurtado y Amores 1984: 161). Corresponde al tholos de las Canteras, perteneciente al foco dolménico de Gandul, Junto a Alcalá de Guadaíra. Algo más al sur, el sector IV dispone de un pequeño foco dolménico en el término municipal de Utrera, con tumbas de corredor y falsa cúpula en Cruz del Gato I, II y III. En el tholos II de los tres señalados se documentó también un "ídolo" placa (IAPH 2000), lo que marca de nuevo un punto de coincidencia de un monumento funerario y de una de estas figurillas indicadoras de duelo. Los datos mencionados hasta ahora marcarían, pues, el límite máximo del semicírculo oriental, una frontera distante donde es evidente que ya Valencina no manifestaba gravedad alguna sobre los grupos humanos que tuvieran que dar sepultura a sus difuntos.

El análisis del semicírculo occidental revela una situación parecida a la ya descrita. Aquí el sector más al sur corresponde al V, que está ocupado en su mayor parte por un antiguo golfo colmatado en el Holoceno reciente por los limos salitrosos de la marisma bética. Por ello carece de ítem funerario alguno, debiendo reconocerse por esta parte la frontera necesariamente en la línea litoral de entonces, básicamente conformada por el flanco sur de la meseta del Aljarafe. Un poco 


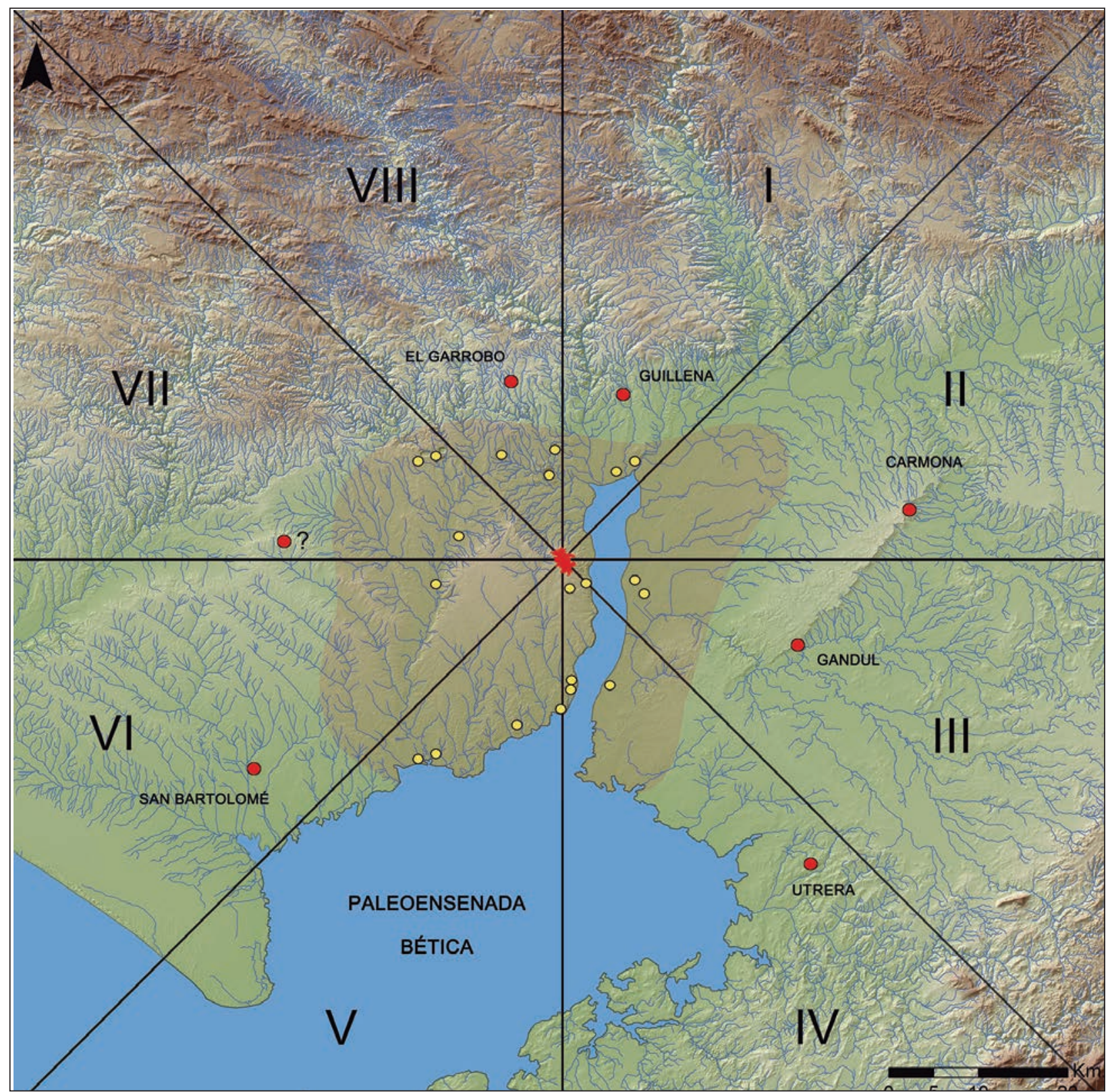

Figura 2. Distrito funerario de Valencina. En la periferia inmediata de Valencina (en el centro) se sitúan los asentamientos que la usarían como cementerio común. En un círculo más alejado se ubican ya las necrópolis de otros territorios.

hacia el oeste, en el sector VI el yacimiento más inmediato a Valencina con registro funerario es San Bartolomé, junto a la localidad onubense de Almonte. Aunque este enclave se conoce sobre todo por su metalurgia protohistórica, cuenta con una primera fase de la Edad del Cobre. Se trata de numerosas oquedades interpretadas como cabañas semiexcavadas (García Sanz y Fernández Jurado 1999). No obstante, algunos de estos hoyos eran tumbas que contenían inhumaciones individuales. No existen en este punto materiales campaniformes, correspondiendo sus ajuares cerámicos de cronología más precisa a los clásicos platos de gran diámetro y borde grueso del horizonte de Valencina. San Bartolomé constituye uno de los yacimientos más alejados de cuantos servirían para dibujar los confines máximos del dominio funerario de Valencina, o más bien un ámbito que escaparía ya a la seducción ejercida por esta gran necrópolis. En el sector VII el documento funerario más cercano lo materializa un "ídolo" cilíndrico vinculado por determinados estudiosos locales al municipio de Aznalcóllar (Rendón 1994: 54-55). Aunque no se conoce su procedencia exacta, ciertas referencias parecen indicar que pueda corresponder a algún yacimiento situado en las campiñas que se extienden desde esta población hasta Tejada la Nueva, Escacena del Campo y Paterna. Precisamente en esta fértil comarca agrícola se conoce un yacimiento calcolítico en el Cerro de la Matanza, promontorio algo más destacado que el conjunto de suaves colinas que caracterizan el paisaje local; pero 
no está claro si procede de aquí el mencionado "ídolo". Por tanto, debemos reconocer que el sector VII carece aún de la precisión con que cuentan los otros segmentos del círculo a la hora de identificar núcleos funerarios distintos del ubicado en Valencina. Finalmente, en el sector VIII puede señalarse como límite máximo del territorio que estamos intentando definir el dolmen de El Toril, en el término municipal de El Garrobo, que corresponde al tipo definido como galería cubierta (IAPH 2000). En línea recta, todos estos cementerios enumerados se sitúan a una distancia de Valencina que excede normalmente los 25/30 km (tabla 1). Sólo los del flanco norte se encuentran más cerca, lo que puede deberse a las dificultades de comunicación que presentan comúnmente las zonas montañosas de la Sierra Morena sevillana.

\section{Sobre EL Distrito FUnerario de VALEnCina}

La ocupación prehistórica más intensa de las márgenes del Guadalquivir en el sector de su viejo estuario y en las orillas de la paleoensenada bética, antiguo golfo hoy colmatado por sedimentos fluviales, aconteció en la Edad del Cobre. Las prospecciones realizadas en las dos orillas del río acreditan un número de asentamientos extremadamente superior a la fase neolítica precedente, conocida sólo por muy pocos enclaves (Gavilán y Escacena 2009: 336-346). Con posterioridad al Calcolítico, la población experimenta un retroceso importante, cuyas razones se han analizado en algunos sectores de la zona (García Rivero y Escacena 2015).

Desde la instalación del Holoceno, el extremo más septentrional del estuario del Guadalquivir corresponde a la localidad sevillana de Alcalá del Río, donde se encuentra el primer punto vadeable del cauce fluvial aguas arriba de la desembocadura. En este sector de cabecera se conoce el yacimiento calcolítico de La Angorrilla, que cuenta con un conjunto numeroso de estructuras subterráneas rellenas de distintos materiales arqueológicos y de restos óseos de animales domésticos (Gavilán 2007). Estos últimos no corresponden a esqueletos completos, pues aparecen cortados como señal evidente de que se trata de piezas de consumo. De todas formas, no sabemos si estas oquedades son simples basureros domésticos o el resultado de ofrendas religiosas y/o de otros ritos sociales. Descartada en muchas ocasiones la idea de que sean simples hoyos de limpieza, se está abriendo paso cada vez más la propuesta de poder ver en estos "campos de silos" la huella de celebraciones colectivas que reunirían la población dispersa en actos de cohesión comunal (Gavilán 2007: 63-66; Benítez de Lugo y Mejías 2015: 122). En cualquier caso, lo que ahora importa es constatar la presencia en este sitio de un asentamiento de la Edad del Cobre, ubicado en la margen derecha del Guadalquivir, que carece de enterramientos humanos en toda la superficie hasta ahora excavada.

Al sur de La Angorrilla, pero también en la orilla derecha del Guadalquivir, hace tiempo que se conoce un enclave calcolítico en el sitio conocido como Las Arenas, en el término municipal de La Algaba. De este yacimiento se cuenta sólo con hallazgos superficiales, y de él se ha valorado especialmente su cerámica campaniforme. Según D. Ruiz Mata (1978-79: 41) nació en "plena Edad del Cobre", fase que equivale a la que en el pasado siglo se consideraba "precampaniforme" o anterior al Cobre Final. Por eso contiene también materiales similares a los de Valencina. Es posible que existiesen aquí en su día estructuras siliformes, características de esta época en todo el mediodía ibérico. De hecho, Ruiz Mata (ibidem) señala el hallazgo de vasijas enteras que podrían proceder de cavidades subterráneas de este tipo. Pero es la ausencia de restos humanos, nunca señalados en el yacimiento, lo que sugiere su catalogación como poblado. Aun así, la presencia de campaniforme relativamente tardío podría deparar el hallazgo futuro de enterramientos, que corresponderían a la fase en que Valencina pudo haber perdido su condición de cementerio centralizado y único de la zona.

Aguas abajo del Guadalquivir, también en su margen derecha y muy cerca de Valencina, se ha excavado un asentamiento calcolítico en El Zaudín (Tomares), cuyos resultados permanecen aún inéditos. El informe preliminar de los trabajos, depositado en la

\begin{tabular}{|c|c|c|}
\hline SECTOR & NECRÓPOLIS & DISTANCIA \\
\hline I & Dólmenes de Guillena & $21 \mathrm{~km}$ \\
\hline II & Carmona & $32 \mathrm{~km}$ \\
\hline III & Gandul (Alcalá de Guadaíra) & $29 \mathrm{~km}$ \\
\hline V & --- & -- \\
\hline IV & Dólmenes de Utrera & $45 \mathrm{~km}$ \\
\hline VI & San Bartolomé (Almonte) & $43 \mathrm{~km}$ \\
\hline VII & Ídolo de Aznalcóllar & ¿? \\
\hline VIII & Dolmen del Toril (El Garrobo) & $20 \mathrm{~km}$ \\
\hline
\end{tabular}

Tabla 1. Cuadro de distancias en línea recta entre Valencina y las necrópolis de su periferia lejana. 
Delegación Provincial de Cultura de Sevilla, cita como único resto óseo humano el hallazgo dentro de un "silo" de un cráneo delimitado por dos piedras que provocaron su aplastamiento. Se trata de un dato que, más que una verdadera tumba, sugiere un depósito ritual de otro tipo. Algo al este de dicho enclave está documentado un hábitat igualmente de la Edad del Cobre en los niveles arqueológicos más profundos del Carambolo. La asignación calcolítica de algunos de sus materiales se debe también a D. Ruiz Mata (1978-79: 41-46), quien precisó la fecha incierta avanzada en su día por Carriazo (1973: 226-230 y 565). Aquí, las últimas excavaciones han sacado a la luz diversas estructuras calcolíticas bajo el santuario fenicio (Fernández Flores y Rodríguez Azogue 2010: 210-213). Por sus relaciones estratigráficas, a esta fase atribuyen los excavadores la inhumación de un niño de menos de cinco meses, con lo que estaríamos ante el único caso cercano a Valencina con evidencia funeraria. Este dato es especialmente interesante dada la escasez en Valencina de sepulturas infantiles, porque evidenciaría una edad con la que aún se carecía de derecho a disponer de tumba en el cementerio comunitario.

Una ausencia total de enterramientos se ha constatado también en lo excavado y prospectado hasta la fecha en Coria del Río, con sendos yacimientos en dos cabezos colindantes: Cantalobos y Cerro de San Juan. En Cantalobos, el más al norte, se han registrado elementos del Cobre, por ejemplo los típicos platos de borde almendrado tan característicos de Valencina. Esta misma datación puede sostenerse para el Cerro de San Juan, inmediatamente al sur, gracias a la presencia también de estas fuentes de amplio diámetro. Aunque se trata en este segundo caso de fragmentos cerámicos en posición secundaria, aquí está bien documentada en cambio la fase final del Calcolítico y la transición al Bronce Antiguo. En este caso se ha constatado una importante presencia de vasijas campaniformes en la base de la estratigrafía, muy fragmentadas como corresponde al registro de una zona de hábitat intensamente frecuentada (García Rivero y Escacena 2015). A estos dos enclaves puede sumarse algo más al sur, en la cercana localidad de La Puebla del Río, el sitio excavado por J. de M. Carriazo (1966: 311) en la Estacada de Alfaro, con algunos materiales calcolíticos procedentes de diversos hoyos que tampoco suministraron restos funerarios (Escacena 2007: 15). En este municipio se conoce también el asentamiento inédito de Cañada Fría, con platos de borde engrosado o almendrado como los clasificados por Ruiz Mata (1975) para la fase del Cobre de Valencina. Este yacimiento es uno de los pocos conocidos algo al interior del Aljarafe, ya que la ocupación calcolítica de esta comarca se limitó en su mayor parte a sus contornos este, junto al Guadalquivir, y oeste, junto al Guadiamar.

Para acabar con la zona ribereña del Guadalquivir es necesario mencionar lo conocido en la margen izquierda del paleoestuario. Aquí destacan por el norte unos cuantos puntos situados en la propia Sevilla y sus inmediaciones. Del propio casco urbano proceden algunos materiales neolíticos y calcolíticos en posición secundaria (Escacena y Tabales 2015: 52-54), pero podemos destacar en este caso fundamentalmente dos enclaves: el Parque Miraflores (Lara et al. 2004) y la antigua Universidad Laboral (Fernández Gómez y Alonso de la Sierra 1985). En ninguno de ellos consta el hallazgo de "ídolos" ni de sepulturas. Río abajo se ha constatado una ocupación calcolítica junto a la Torre de los Herberos, en el término municipal de Dos Hermanas (Fernández Gómez et al. 1997: 137-138). Este asentamiento está situado precisamente frente al Cerro de San Juan de Coria del Río, donde el paleoestuario presentaba un estrangulamiento conocido como "Estrecho de Coria" (Arteaga et al. 1995: 109).

El Aljarafe está bien delimitado en su flanco oeste por la cuenca del Guadiamar. En este sector destaca un asentamiento que pudo tener cierta importancia durante la Edad del Cobre y que ocupa el ángulo suroccidental de la meseta. Corresponde a la localidad de Aznalcázar, donde los datos más claros sobre una ocupación calcolítica proceden del sur del casco urbano (Rodríguez de Guzmán y Cáceres 1988: 377). Además, el Museo Arqueológico de Sevilla conserva un vaso campaniforme completo de esta localidad, aunque de sitio exacto desconocido (Serna 1989: 76). No puede descartarse que este recipiente formara parte de un ajuar funerario dada su buena conservación. A este sitio se suma el cercano yacimiento de Chillas, en Villamanrique de la Condesa, con un estrato de plena fase calcolítica y sin enterramientos conocidos bajo otro nivel del Hierro Antiguo (Pellicer 1986: 246). Aquí no hay campaniforme, pero sí diversos tipos de platos de las variedades más registradas en Valencina. Parece que entre Aznalcázar y Chillas, uno a cada lado del Guadiamar, controlaban la antigua desembocadura de este río en la paleoensenada bética.

Subiendo esta vía fluvial, hoy tributaria del Guadalquivir y que nace en las cercanías del Castillo de las Guardas, en Sierra Morena, podemos ubicar también diversos hábitats calcolíticos. Se trata ahora de un ámbito menos conocido que la ribera del Guadalquivir, aunque algunas zonas están más inspeccionadas que otras. Este escaso conocimiento no se debe en realidad a la falta de trabajos arqueológicos, sino al hecho de que sus resultados no se han publicado tan extensamente como los de otras áreas. Esto nos obliga a ser algo más imprecisos al analizar determinados ámbitos locales. Aquí, el punto calcolítico más al sur corresponde a Chichina, en Sanlúcar la Mayor, donde existió una necrópolis de cistas en el Bronce Antiguo superpuesta a un asentamiento anterior fechado en la Edad del Cobre. Este poblado inicial ha proporcionado huellas de estructuras de habitación y diversos materiales cerámicos claramente calcolíticos, 
sin campaniforme (Fernández Gómez et al. 1976: 373 374). Sólo un poco más al norte de este enclave, se han documentado diversos puntos con ocupación calcolítica en el término municipal de Olivares, también mirando al Guadiamar, aunque los sitios concretos y sus materiales permanecen aún inéditos. Se trata al parecer de pequeños hábitats con abundante cerámica en superficie, especialmente platos de borde engrosado y/o almendrado, aunque sin campaniforme y sin restos óseos que sugieran necrópolis asociadas. Cuando se accede a la cuenca media del Guadiamar, a la altura de la zona minera de Aznalcóllar, tampoco se conocen enterramientos calcolíticos, aunque sí diversos yacimientos interpretados como poblados. En esta parte del territorio se ha investigado con más profundidad el de Los Páramos, un asentamiento calcolítico sobre el que se superpone, como en Chichina y en otros enclaves aquí reseñados, una necrópolis con cistas y fosas del Bronce Antiguo (Hunt 2000); pero la carta arqueológica de esta localidad cita también como yacimiento de la Edad del Cobre El Torreón (Hunt et al. 2017). De las explotaciones mineras prehistóricas de esta localidad procedía precisamente el metal manipulado en el taller de Valencina (Nocete et al. 2008: 718), por lo que parece razonable incluir esta zona en su órbita territorial.

Al norte de Valencina se sitúa el Corredor de Gerena, una comarca de fértiles tierras que comunica la cabecera del estuario del Guadalquivir con el sector minero de Aznalcóllar y que sirve de límite septentrional a la comarca del Aljarafe. En este flanco apenas se han excavado yacimientos calcolíticos. Los conocidos por prospecciones superficiales corresponden a poblados de diverso tamaño. Destacan el Cerro del CastilloMesa Redonda, que ocupa el propio casco histórico de Gerena, y El Turuñuelo. Interpretados como hábitats que explotan tierras muy ricas para la agricultura, no consta el hallazgo en ellos de enterramientos ni de "ídolos" (Guisado et al. 2010'). Sabemos también que el granito usado en algunos megalitos de Valencina pudo proceder precisamente de los afloramientos de esta roca situados en Gerena y en sus cercanías. Este hecho se ha constatado, por ejemplo, en los hipogeos de Matarrubilla (Collantes de Terán 1969: 48) y La Pastora (Cáceres et al. 2013: 221). Por esta razón incluimos el Corredor de Gerena en el territorio de la gente que tenía a Valencina como cementerio corporativo. En esta depresión, pero aún más cerca de Valencina, se encuentra también el yacimiento de Cobre Las Cruces. Se trata de nuevo de un asentamiento calcolítico sin registro funerario, aunque más tarde, una vez abandonado como hábitat, se le superpusieron cistas con inhumaciones individuales fechadas en el Bronce Antiguo (Hunt 2012: 66).

\section{VALENCINA COMO NECRÓPOLIS MANCOMUNADA}

Al análisis de todos estos enclaves del territorio periférico, que indica hasta la fecha una ausencia casi total de documentación funeraria genuina, hay que contraponer sin duda el registro arqueológico de la propia Valencina, revelador precisamente todo lo contrario. A la hora de dar cuenta de los rasgos particulares de este enorme enclave podemos dividir el conjunto en dos grandes lotes: las construcciones pétreas (megalitos y otros modelos de menor envergadura) y las cavidades excavadas directamente en el subsuelo. Como las primeras no han ofrecido dudas sobre su papel mortuorio, profundizaremos en el problema que representan las segundas, sobre todo en los aspectos que se refieren a su función y a su uso como estructuras donde se depositaron numerosos "ídolos".

Estas figurillas rituales muestran en Valencina una distribución que aclara muchos puntos importantes para nuestra hipótesis. Del conjunto hasta ahora conocido se ha publicado hace pocos años un catálogo muy completo por V. Hurtado (2013), al que puede añadirse alguna pieza dada a conocer con posterioridad (Murillo-Barroso et al. 2015). La información que nos interesa de este corpus se encuentra dispersa en un amplísimo repertorio bibliográfico cuya cita excedería los límites del presente artículo. Por ello, hemos sintetizado los datos en un cuadro de fácil consulta que recoge la interpretación funcional hasta ahora propuesta para sus contextos de procedencia (tabla 2). Si no se ha dudado nunca de que los megalitos y otras construcciones pétreas sean realmente sepulturas, unas veces porque de hecho contienen inhumaciones y otras porque sabemos que era éste su destino principal según se ha observado en múltiples casos similares, para las

\begin{tabular}{|c|c|}
\hline TIPO DE ESTRUCTURA & $\mathbf{N}^{\mathbf{0}}$ DE PIEZAS \\
\hline Cabañas & 2 \\
\hline Silos & 9 \\
\hline Silos/Pozos & 4 \\
\hline Fosos/Zanjas & 4 \\
\hline Desconocida & 17 \\
\hline TOTAL & $\mathbf{3 6}$ \\
\hline
\end{tabular}

Tabla 2. Contextos de procedencia de los "ídolos" de Valencina. La terminología funcional de las estructuras corresponde a la publicada por los distintos autores que los han dado a conocer.

6 En http://3web.dipusevilla.es/planeamiento/gerena10/045

PGai.htm. Consulta realizada el 28/09/2018. 
estructuras excavadas en el subsuelo tenemos una gran variedad de interpretaciones, sosteniéndose la mayor parte de las veces que los cadáveres aparecidos en ellas demostrarían reutilizaciones de elementos destinados en primera instancia a funciones no mortuorias. El caso más típico es el de los "silos" con registro funerario, siempre tenidos por graneros que, una vez inutilizados como tales, eran usados como sepulturas. Pero los roles atribuidos a este conjunto de hoyos se sustentan muchas veces en aceptaciones acríticas de su función, deducida sólo de su apariencia formal y basada en hipótesis funcionalistas que no han tenido en cuenta casi nunca que un mismo diseño final pueda ser el producto de intenciones muy distintas. Así que conviene resaltar ahora que todas esas cavidades no son necesariamente almacenes de grano, viviendas o fosos defensivos, pudiendo corresponder a tumbas propiamente dichas -usadas o no-, a fosas donde depositar ofrendas o restos de banquetes funerarios y a recintos delimitadores de subáreas mortuorias.

En Valencina se han referido distintas estructuras hipogeas de esta clase, cuyos nombres se deben en parte a la tradición historiográfica y al supuesto papel que desempeñarían en un sitio pensado siempre, y de forma axiomática, como gran poblado con su correspondiente necrópolis. Algunas de estas construcciones se han tenido por unidades domésticas familiares, casi siempre con el nombre de "cabañas" o "fondos de cabaña"; otras veces se han descrito como "silos" agrícolas; también como "pozos", algunos destinados en concreto a la captación de aguas subterráneas en primera instancia; y finalmente como "zanjas" o "fosos" para la defensa del hábitat. Las estructuras tenidas por viviendas cuentan para su interpretación con un grave inconveniente, el hecho de que sus características morfológicas y sus dimensiones las hacen muchas veces inapropiadas para su uso habitacional. Sorprende cómo han podido calificarse como tales casas unos agujeros que a veces no alcanzan ni los dos metros de diámetro, y cuyas pareces inclinadas hacia el interior impedirían que una persona de talla media deambulara erguida por más de la mitad de su espacio interior. Por otra parte, sus sedimentos internos demuestran que no se retiraba la supuesta basura, cuestión que choca con lo conocido en estructuras calcolíticas bajoandaluzas que sí tienen más clara su función de vivienda. Estas otras sí disponían de los correspondientes muros de piedra y de puertas de acceso, y en ellas se llevaban a cabo con asiduidad labores de limpieza (Escacena y De Frutos 1981-82: 169). Además, las estratigrafías localizadas dentro de los hoyos de Valencina interpretados como chozas semisubterráneas presentan muchas veces interfacies tan irregulares que harían imposible el desenvolvimiento cotidiano de quienes las ocuparan. A esto se añade la práctica inexistencia en todo el yacimiento de superposiciones diacrónicas de estructuras de habitación, rasgo que habría originado durante un milenio una potente estratigrafía vertical, un tell que jamás se ha constatado. Por otra parte, ni los análisis sedimentológicos ni los estudios tafonómicos de los restos de fauna avalan la función como auténticas viviendas de muchas de las estructuras negativas clasificadas como tales (García Sanjuán y MurilloBarroso 2013: 128), que por otra parte casi nunca se encuentran agrupadas en conjuntos parecidos a los que caracterizan a otros poblados calcolíticos bien conocidos en el sur de la península ibérica. A este respecto, el registro supuestamente habitacional de Valencina no resiste una mínima comparación con lo observado en Los Millares, como ya hemos indicado, pero tampoco con los rasgos constatados en las casas de Marroquíes Bajos, en Jaén (Zafra et al. 1999: 8388) o en las de San Blas de Cheles, en Badajoz (Hurtado 2004: 147-153).

Un hecho del mayor interés para nuestro análisis Un hecho del mayor interés para nuestro análisis deriva del estudio pormenorizado de la procedencia concreta de los "ídolos" hallados en la propia Valencina. Sus contextos arqueológicos carecían hasta ahora de un análisis global de referencia, que hemos tenido que elaborar para el presente artículo. De hecho, su estudio se ha centrado más en clasificarlos fenéticamente. Así que debemos abordar aquí este aspecto clave de nuestra hipótesis. En síntesis, el inventario publicado consta de 36 piezas de bulto redondo, que corresponden tanto a hallazgos fortuitos como a documentación procedente de trabajos científicos. En el conjunto del yacimiento, todas muestran una distribución local sin relación aparente alguna con la clásica división del sitio propuesta por Arteaga y Cruz-Auñón (1995), según la cual tendríamos una zona de hábitat y otra de enterramientos (fig. 3). El estudio de este problema permitirá comprobar si existe relación alguna entre esas figurillas y sus contextos, como cabe esperar, y qué puede deducirse de ello. Hay ejemplares con procedencia desconocida, aunque atribuidos a Valencina. Otras veces consta fehacientemente su hallazgo superficial en el yacimiento, aunque no se tenga seguridad plena sobre el sector concreto de aparición. Ambos lotes componen un total de 8 casos, de los que prescindiremos por la mala calidad científica de sus referencias contextuales y por la posibilidad, por tanto, de que desvirtúen las conclusiones globales.

Como Valencina se ha considerado siempre un gran poblado con su correspondiente necrópolis, las distintas publicaciones han dividido siempre los lugares de intervención arqueológica en estas dos categorías, en análisis más guiados por la fuerte inercia historiográfica que por la realidad de los datos. De ahí que respetemos en principio tal dicotomía para profundizar en los contextos que ahora nos interesan. Distinguiremos por tanto dos lotes de figurillas: las halladas en estructuras definidas como "de habitación" 


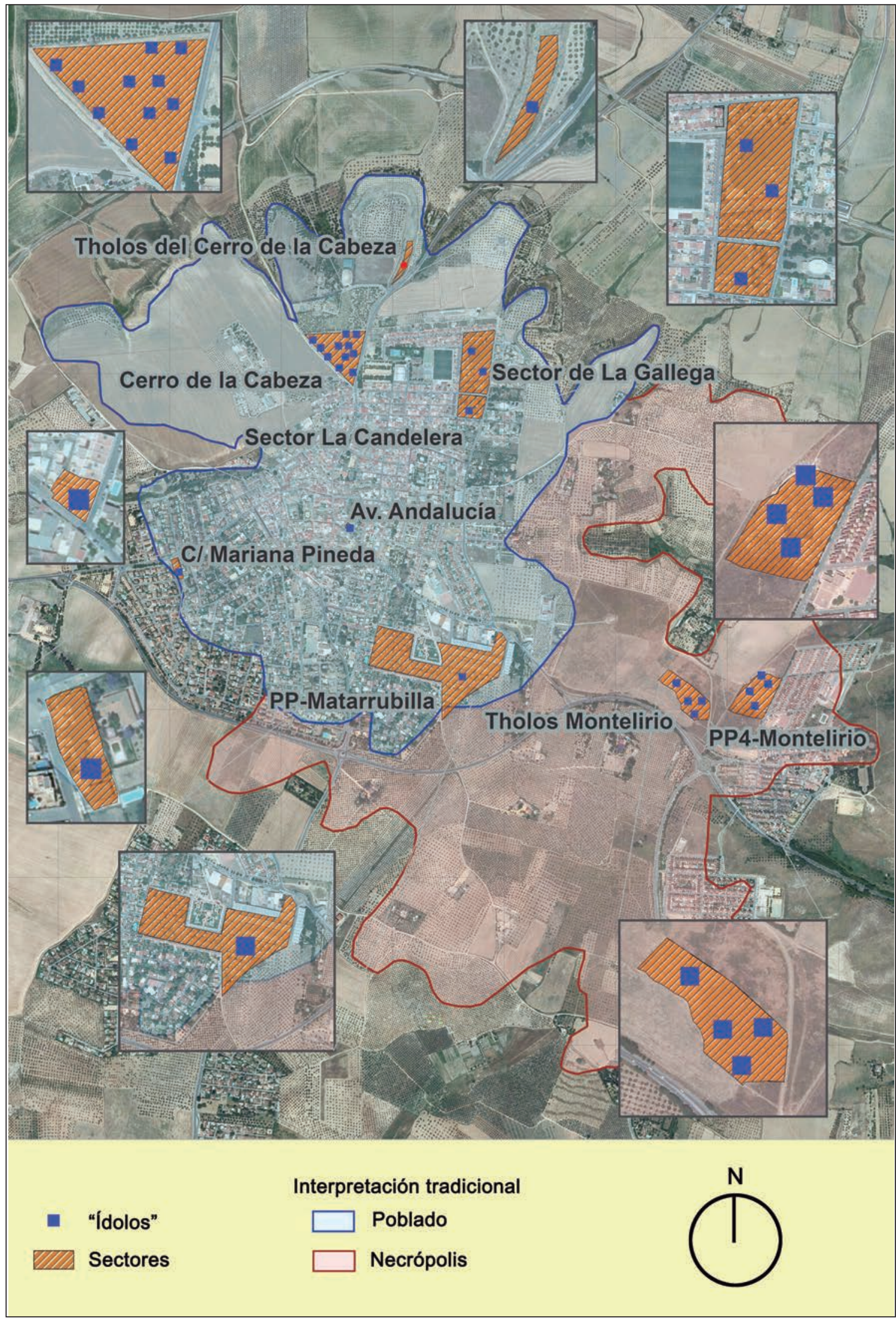

Figura 3. Los "ídolos" de Valencina se reparten por todo el yacimiento, sin que exista una diferencia notable entre las dos zonas (poblado y necrópolis) de la interpretación clásica. Sólo se observa un vacío relativo en el núcleo antiguo del casco urbano, donde también son más escasas las tumbas. Este hecho puede deberse a la simple destrucción del registro tras la fundación medieval de municipio. Información tomada básicamente de dos grandes catálogos que se complementan: Fernández Gómez y Oliva (1980) y Hurtado (2013). 
y las procedentes de ambientes funerarios. Insistimos en que esta división está motivada por las referencias usadas por casi todos los autores consultados, que han considerado las zanjas, los pozos, los "silos" y las “cabañas", además de otras oquedades, muestras aceptadas de estructuras "domésticas", no funerarias o sin carácter simbólico, con la honrosa excepción -muy importante para nuestra tesis- de quienes han dudado seriamente de tan elemental propuesta (Jiménez y Márquez 2006: 39-40; Márquez y Jiménez 2010).

La diferenciación establecida en Valencina, a nivel espacial, entre un área habitacional y productiva y otra funeraria se basa en que la mayor parte de las estructuras megalíticas se encuentran en la zona sur-sureste y las dedicadas al trabajo en el sector norte, pero diversos especialistas han criticado tal propuesta al no cumplirse sistemáticamente. De hecho, existen tumbas repartidas por todo el yacimiento aunque las megalíticas tiendan a agruparse sobre todo en el flanco más próximo al Guadalquivir. Por otra parte, los "ídolos" también se distribuyen por todas partes, y no sólo por el sector funerario de la división tradicional. Su hallazgo exclusivo en el sector sureste del yacimiento sería por lo tanto esperable si la necrópolis ocupara sólo esa parte, pues hemos visto la fuerte vinculación de estas figurillas al mundo de la muerte. Por lo demás, los defensores de la división del sitio en dos partes funcionalmente diversas asumen, de manera explícita unas veces o de forma implícita en otras ocasiones, la reutilización frecuente de estructuras de carácter económico para ubicar en ellas posteriores enterramientos. Según hemos visto, dicha propuesta se aplica sobre todo a cavidades que habrían tenido un primer uso como "silos" para almacenar cereales.
De las 28 figurillas que ofrecen contextos conocidos -y siguiendo siempre lo publicado- 18 corresponderían a estructuras catalogadas como no funerarias y 10 a contextos claramente mortuorios o muy relacionados con ellos (fig. 4). Se trata de una distribución muy extraña si se tiene en cuenta la relación de estas pequeñas imágenes con el mundo simbólico, normalmente aceptada incluso si su significado específico no tuviera que ver directamente con el más allá. Por otro lado, sólo una de las localizadas en ambientes funerarios claros, la placa de pizarra del Cerro de la Cabeza, no se ubica en la zona de Montelirio, un sector que carece de dudas sobre su función como necrópolis. Es normal que las piezas encontradas en las excavaciones más recientes hayan recibido mayor atención contextual por parte de sus excavadores o de quienes las han publicado. Son un claro ejemplo de esta situación precisamente las del referido sector de Montelirio, investigado ya en el presente siglo. En estos casos las figurillas se ubican en las cámaras funerarias de los distintos hipogeos o en oquedades claramente vinculadas a diversas tumbas, y siempre formando parte de los ajuares mortuorios o de depósitos rituales relacionados con las sepulturas. En este límite sureste del yacimiento destacan dos piezas de oro interpretadas como "ídolos" aunque carecen de "tatuaje facial" (Murillo-Barroso et al. 2015; Murillo-Barroso 2016: 287-308), pero también representaciones pictóricas de oculados, con posibles rasguños de duelo en algún caso, en los ortostatos 17 y 18 del hipogeo monumental de Montelirio (Bueno et al. 2016: 371-373), que aquí no hemos contabilizado como "ídolos" por no ser estatuillas de bulto redondo aun tratándose de la de la misma manifestación funeraria, esta vez expresada en las paredes de la propia tumba.

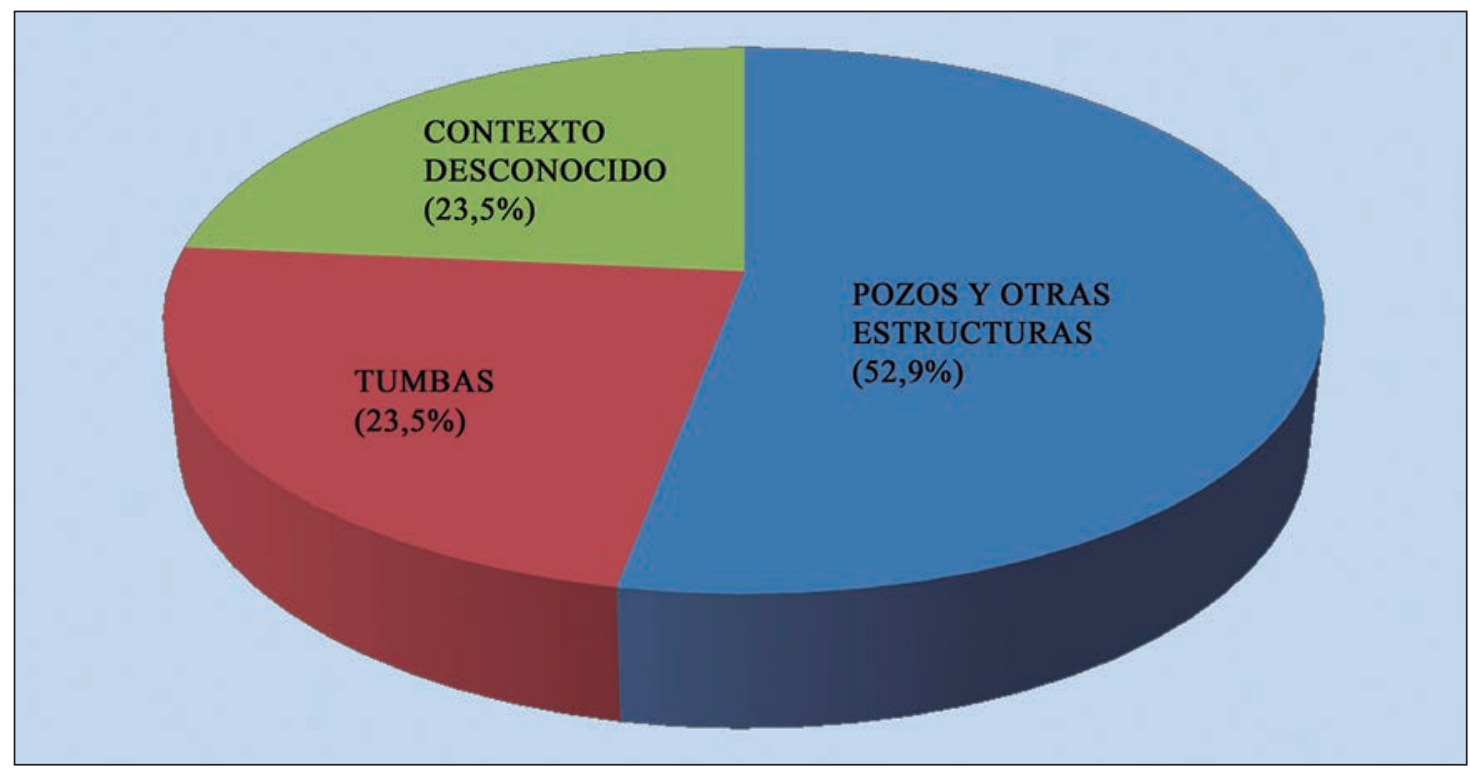

Figura 4. Distribución proporcional de los “ídolos” de Valencina, con indicación del papel de cada contexto señalado en las publicaciones de referencia. 
Los "ídolos" de Valencina hallados en "silos" y "pozos" estaban contenidos en unos rellenos considerados muchas veces meros residuos domésticos. De ser cierta esta lectura de sus contextos estratigráficos inmediatos, extraña de nuevo que figurillas tan elaboradas y suntuosas se arrojaran a esas oquedades en calidad de simple basura. Por otra parte, la interpretación de estos "silos" como almacén para cereales ha estado muy vinculada a la explicación marxista de Valencina como centro político de un estado surgido a orillas del Guadalquivir inferior (Nocete 2001). Tales estructuras subterráneas se han reconocido en muchas ocasiones como verdaderos pósitos (Mejías 2011: 82$86)$, lo que supondría la existencia de graneros colectivos para toda una región. Sin embargo, esto choca con la escasez paralela de viviendas, que en Valencina han sido señaladas en un número muy escaso y con frecuencia atribuidas más al Bronce Antiguo que al Calcolítico. Curiosamente, el contraste numérico entre la supuesta abundancia de "silos" y la falta de estructuras domésticas puede aplicarse también a la comparación entre la cantidad de estas últimas y el número de sepulturas, casi inexistentes las primeras y abundantísimas las segundas. En Valencina, estos hipotéticos "silos" nunca han aparecido con abundante materia orgánica en su interior que pueda identificarse como restos de cereal descompuesto, y en cambio se han documentado en ocasiones restos óseos muy selectivos, entre ellos cuernos de caprinos y de ciervos. Tampoco suelen mostrar revestimientos internos especiales para aislarlos de la humedad o vasijas enteras depositadas en su interior en las que guardar el grano. Sólo su forma abovedada con acceso cenital es la responsable de que se siga repitiendo su nombre. Sin embargo, los estudios recientes sobre el tema han puesto en tela de juicio que estas estructuras fueran realmente graneros, porque su aceptación como tales almacenes de cereal deriva de una tradición historiográfica que fabricó un axioma con dicha identificación y que consagró el nombre de Cultura de los Silos para los yacimientos donde tales hoyos aparecían con profusión, como han demostrado J.E. Márquez y V. Jiménez (2010: 21-24). Así y todo, la fuerte inercia de esta tesis tradicional sigue imperando de forma irreflexiva. Demostrar que los de Valencina o los de muchos otros sitios andaluces son auténticos silos exigiría las pruebas pertinentes; su forma no es razón suficiente para aceptar sin más la hipótesis. De hecho, es posible atribuirles otras funciones.

En relación con el acopio de grano, algunos experimentos han señalado cómo pudo preservarse éste en esas cavidades subterráneas. Así, éstas deberían disponer de enlucidos aislantes realizados con arcillas impermeables (Reynolds 1988) o, mejor aún, con paja (Alcalde y Buxó 1992). El mantenimiento de la cosecha en tales condiciones depende además de que se logre cerrar los contenedores herméticamente. Si se consigue, el producto guardado desprende dióxido de carbono conforme agota el oxígeno, lo que impide que medren las bacterias (Buxó 1997: 181). En estas circunstancias, las semillas del núcleo central conservan con menores dificultades su capacidad alimenticia y su poder germinativo. Serán éstas, en consecuencia, las idóneas para la siguiente siembra, pues su capacidad para nacer dura unos tres años. Si en este ambiente la temperatura no excede los $15^{\circ} \mathrm{C}$ y la humedad relativa se mantiene en torno al $18 \%$, se alcanzan óptimas condiciones para el stock. Cualquier cambio de estas variables aminora la capacidad germinativa del cereal e incrementa sus posibilidades de deterioro, perdiéndose como sustento y como semilla ante los ataques bacterianos o de hongos e insectos. Su potencial reproductor persiste también mediante la variación compensatoria de estos índices. Los hongos no se desarrollarán con temperatura superior a $20^{\circ} \mathrm{C}$ si se consigue una humedad inferior al 10\%; y unas condiciones entre $5^{\circ}$ y $10^{\circ} \mathrm{C}$ impedirán la vida a los insectos si la humedad supera el 20\% (Buxó 1997: 178-180). Así que aceptar que las oquedades piriformes de Valencina son verdaderos silos requiere la necesaria demostración de que todos estos exigentes requisitos son posibles, cosa que aún no se ha hecho. Por eso hemos querido entrar aquí en tantos detalles relativos a este extremo; no tanto para negar automáticamente que los "silos" sean de uso agrícola como para suscitar una reflexión más profunda sobre su función específica.

En muchos asentamientos coetáneos a Valencina o cercanos a su cronología se han localizado numerosas zanjas, para las que se han ofrecido distintas interpretaciones. Se ha defendido, por ejemplo, que formaron parte de murallas o que fueron canalizaciones de drenaje y conducción de aguas. J.E. Márquez y V. Jiménez (2010: 161-162) han recogido los diversos sitios donde tales fosos, de sección en $\mathrm{V}$ o en $\mathrm{U}$ y con variados tamaños y disposición, se han tenido por elementos defensivos que precedían a las murallas propiamente dichas. A esta función habría que añadir la posibilidad de que formaran parte de cercas para el ganado, una idea descartada para el sitio onubense de Papa Uvas (Martín de la Cruz 1985: 154-156). Pero hoy sabemos que su cantidad y su distribución en Valencina ofrecen un "laberinto" difícil de comprender desde estas hipótesis. De hecho, tampoco se han localizado nunca en este yacimiento sevillano paramentos de piedra adosados y paralelos a dichos fosos, ni terraplenes de barro o empalizadas que sustituyeran a defensas pétreas. Además, la aparición de "silos" a ambos lados de esas estructuras negativas invalidaría su hipotética misión protectora, pues de ser así los graneros deberían ubicarse sólo al interior de los supuestos recintos defensivos y no a ambos lados de los mismos. Un argumento parecido podemos emplear en contra de que fueran sistemas de drenaje de los mencionados "silos", como se sostuvo en los comienzos de 
su investigación (Ruiz Mata 1983: 185; Fernández Gómez y Oliva 1985: 114), ya que los fondos de estos últimos son en ocasiones más profundos que los de las zanjas que los deberían desaguar.

Todas las dudas recién expuestas sobre las estructuras subterráneas abiertas en época calcolítica en Valencina no ofrecen de momento un papel alternativo al propuesto o aceptado por la mayor parte de quienes han investigado el yacimiento. Pero permiten al menos librarnos del pesado lastre historiográfico que ha convertido en axioma funcional el término consagrado para aludir a ellas. Este hecho afecta especialmente a los "silos", hasta el punto de que el hallazgo de cadáveres en su interior siempre acaba desembocando en la misma propuesta: serían oquedades para almacenar el grano pero reutilizadas posteriormente como tumbas. Y nadie ha pensado que, aun asumiendo su coincidencia formal con los verdaderos silos, sean hoyos excavados con la intención de alojar inhumaciones.

\section{Algunas REFleXiones FinAles}

A partir de todos los datos expuestos sobre el poblamiento periférico de Valencina y de la crítica de la documentación procedente de este enclave, es factible llevar a cabo una propuesta algo más precisa sobre los límites del que hemos denominado "distrito funerario" de Valencina, tarea en la que pueden ayudar ciertas particularidades geográficas de la zona. En este territorio, el Guadalquivir podría haber constituido un elemento potencialmente usado como confín, de forma que a un lado y a otro de su cauce existieran necrópolis grupales distintas. Así, a la Valencina de la orilla occidental correspondería otros focos similares en los sitios ya citados de Carmona y Gandul, que dividirían a partes iguales la comarca de Los Alcores. No obstante, y aun disponiendo el propio Guadalquivir de este hipotético potencial fronterizo que separaría con nitidez los grupos humanos de sus márgenes, su papel histórico posterior fue más bien el contrario, ya que ejerció como aglutinante de poblaciones durante toda la Protohistoria. Por este motivo habría que concederle a Valencina la posibilidad de que gentes de la orilla oriental del río acudieran allí también a cubrir sus necesidades funerarias. Esto parece probable respecto a los asentamientos detectados en la propia Sevilla, caso del Parque Miraflores y de la antigua Universidad Laboral, y en la Torre de los Herberos. Junto a este último enclave, en el municipio de Dos Hermanas, el "Estrecho de Coria" suponía un hito fluvial susceptible de haber representado en la Edad del Cobre el final del río, y a su vez la embocadura del estuario. Por la orilla derecha del Guadalquivir, ya hemos señalado que San Bartolomé de Almonte representó una necrópolis distinta, pues allí sí existe registro funerario calcolítico. En este caso, estaríamos ante grupos que habitan una comarca bastante despoblada a causa de su pobreza edáfica, con un medio boscoso que, más allá del límite sur del Aljarafe, se adentra poco a poco en el actual ecosistema de Doñana. Así que por esta parte es posible que la gente más meridional que se enterraba en Valencina fuera la que habitaba en los dos asentamientos que marcaban la desembocadura antigua del Guadiamar: Aznalcázar y Chillas. Desde todos estos sitios cercanos a la antigua costa, o ubicados a orillas del estuario, el acceso más fácil a Valencina era el medio acuático, fácilmente navegable gracias al impulso de bajada y de subida que proporcionaban las mareas atlánticas.

Si por el oeste el Cerro de la Matanza hubiera sido otra necrópolis comunitaria distinta de la ubicada en Valencina, podríamos asumir que la frontera entre ambos núcleos viniera definida por el Guadiamar, no apto para la navegación en su tramo medio y por tanto carente por esta parte de la capacidad de cohesión de orillas de los ríos con tráfico fluvial. El cauce del Guadiamar es también la línea más clara de separación entre los hipotéticos territorios de Valencina y de la lejana Mesa de la Sepultura de Villarrasa. El propio paisaje del flanco oeste del Aljarafe marca una importante hendidura y un fuerte desnivel al acercarse a este río. A nuestro entender, queda por tanto nuevamente reforzada la posibilidad de que fuera por aquí el límite entre dos distritos funerarios distintos. En consecuencia, podríamos excluir del dominio de Valencina la comarca del Campo de Tejada y, por supuesto, la del Condado, cuyas necrópolis pueden estar aún por identificar en su totalidad. El Aljarafe entero correspondería así al territorio identificable como dependiente de Valencina en sus usos funerarios. No obstante, como el Guadiamar es fácil de vadear por muchos puntos, y su caudal no supone casi nunca una barrera infranqueable, podemos dejar abierta la posibilidad de que algunos enclaves ribereños de su margen occidental también estuviesen vinculados a Valencina, sobre todo por su cercanía y por el indudable prestigio que esta necrópolis pudo tener en todo el Guadalquivir inferior. De esta forma, no deberíamos descartar a priori que Valencina fuera el cementerio del grupo humano que habitó la fase calcolítica de Chichina, en el término municipal de Sanlúcar la Mayor pero en la orilla derecha de dicho río. A este respecto, aunque el Guadiamar se considera el accidente geográfico que marca con mayor precisión la frontera occidental de esta meseta, históricamente algunas localidades emplazadas al oeste del río han reivindicado su pertenencia a la comarca, como ocurre en el caso de Huévar del Aljarafe.

En dirección septentrional se dibuja una línea nítida de necrópolis en las estribaciones meridionales de Sierra Morena, una sucesión de megalitos definida por los conjuntos de El Garrobo y de Guillena, avanzadillas hacia el sur de otros muchos núcleos funerarios dolménicos de la Sierra Norte sevillana como los de 
Alanís, Constantina, Cazalla de la Sierra o Almadén de la Plata, a los que hay que sumar cavidades kársticas también usadas como probables lugares de enterramiento al contar con "ídolos", caso de la Cueva Chica de Santiago, también en Cazalla de la Sierra. La zona montañosa situada al sur de la línea dolménica más meridional, la de El Garrobo-Guillena, acrecienta su pobreza edáfica conforme se aproxima a las actuales poblaciones de Aznalcóllar y Gerena, de ahí que sea prácticamente nula la ocupación calcolítica estable en estos sectores serranos meridionales, muy yermos. Este hecho permite llevar la frontera funeraria de Valencina, en este sector, por el límite sur de Sierra Morena, cuando, según las zonas, cambia la composición de los suelos, ahora más fértiles conforme se identifican con el valle del Guadalquivir y la Depresión de Gerena, o cuando afloran las venas metalíferas en las proximidades de Aznalcóllar. Desde los altos de Valencina se puede observar con extrema nitidez el cambio de ecosistema que representa la Sierra Norte sevillana, transmitiendo la percepción visual de que aquellas montañas son ya otra cosa.

Todos los asentamientos incluidos en la periferia inmediata de Valencina carecen -repetimos- de evidencias funerarias claras. De algunos de ellos se han excavado extensiones razonablemente significativas que, como ocurre en El Zaudín o en La Angorrilla, incluyen numerosas unidades negativas que en su día se abrieron en el suelo, pero que no han ofrecido tumbas. Todos estos sitios están situados, además, a una distancia prudencial de Valencina, nunca tan grande como para necesitar más de tres jornadas en los ritos de despedida de los difuntos, la primera de ida, la segunda de celebración de los funerales y la tercera de vuelta. El territorio así delimitado se configura en un gran espacio donde casi nunca la distancia de Valencina supera los 25/30 km en línea recta (tabla 3). Un repaso a los estudios arqueológicos referidos a este ámbito geográfico revela la inexistencia de megalitos, de otras modalidades de tumbas y de "ídolos". En el fondo, lo que evidencia este registro es la falta de lugares destinados a alojar a los difuntos junto a cada pequeño enclave local, así como la paralela y extraordinaria concentración de sepulturas en Valencina. En el "centro" de dicho espacio esta constante se quiebra de forma brusca en nuestro gran cementerio, donde todos esos ítems funerarios vuelven a aparecer con profusión. En consecuencia, este territorio definiría el "distrito funerario" de Valencina, la comarca cuyos poblados, aldeas y granjas acudirían a enterrar a sus difuntos a dicho enclave. Por estas razones, y por la ausencia en Valencina de elementos arqueológicos que la definan como poblado genuino, proponemos que este enorme yacimiento se considere en esencia la única necrópolis colectiva de todo un territorio social, y posiblemente también lugar identitario de toda una extensa comuni-

\begin{tabular}{|c|c|c|}
\hline YACIMIENTO & MUNICIPIO & DISTANCIA EN KM \\
\hline La Angorrilla & Alcalá del Río & 15 \\
\hline Las Arenas & La Algaba & 12 \\
\hline El Zaudín & Tomares & 3 \\
\hline El Carambolo & Camas & 2 \\
\hline Cantalobos & Coria del Río & 15 \\
\hline Cerro de San Juan & Coria del Río & 16 \\
\hline Estacada de Alfaro & La Puebla del Río & 18 \\
\hline Cañada Fría & La Puebla del Río & 21 \\
\hline Parque Miraflores & Sevilla & 9 \\
\hline Antigua Universidad Laboral & Sevilla & 10 \\
\hline Torre de los Herberos & Dos Hermanas & 17 \\
\hline Aznalcázar & Aznalcázar & 28 \\
\hline Chillas & Villamanrique de la Condesa & 29 \\
\hline Chichina & Sanlúcar la Mayor & 16 \\
\hline Oacimares & 13 \\
\hline Los Páramos & Aznalcóllar & 20 \\
\hline El Torreón & Aznalcóllar & 18 \\
\hline Gerro del Castillo-Mesa Redonda & Gerena & 15 \\
\hline El Turuñuelo & Gerena & 18 \\
\hline Cobre las Cruces & Gerena & 10 \\
\hline
\end{tabular}

Tabla 3. Cuadro de distancias en línea recta entre Valencina y los asentamientos de su distrito funerario conocidos hasta la fecha. 
dad humana. La superficie destinada aquí a cementerio se ubica básicamente en el término municipal de la localidad actual de Valencina de la Concepción, aunque tiene una importante extensión hacia Castilleja de Guzmán y Camas. Pero debemos estar abiertos a que esta amplia necrópolis se vea aún aumentada en futuras investigaciones hacia otras localidades vecinas, en el paisaje de suaves colinas o de cabezos más pronunciados que configura las máximas alturas de la cornisa oriental del Aljarafe (fig. 5).

Para certificar nuestra propuesta debemos esperar la inexistencia de necrópolis calcolíticas a menos de 25/30 km de Valencina, un trecho que equivale a lo que una persona podía recorrer a pie en una jornada de camino según los cálculos llevados a cabo para la las sociedades prehistóricas por M. Ruiz-Gálvez (1992: 96). Esta misma condición debería cumplirse en la distribución de los "ídolos": que, siempre que se hallen en contextos primarios, su lugar de procedencia diste de Valencina al menos esa separación. Paralelamente, sí deberíamos contar en cambio con numerosos asentamientos de diversa índole, los lugares de origen y residencia asidua de la población que recibía sepultura en Valencina. A lo largo de estas páginas hemos intentado demostrar que dichas condiciones están garantizadas por el registro arqueológico hoy conocido, pero certificar la hipótesis exige que estos rasgos no varíen en el futuro. Sólo esperamos posibles excepciones que se limiten a individuos infantiles como el ya citado del Carambolo.

A favor de nuestra explicación de Valencina pueden traerse a colación otros datos ya controlados por la investigación. Nos referimos, por ejemplo, al hecho, constatado en los últimos avances bioarqueológicos, de que la población enterrada en Valencina muestra una gran diversidad, producto del amplio espectro local de su procedencia. Tal hecho sugiere que el nacimiento y primera crianza de los distintos individuos allí sepultados pudo acontecer en ambientes más o menos distantes de la necrópolis donde acabaron finalmente enterrados. Esta acusada variación somática parece cada vez más clara cuando se analizan los restos humanos de Valencina (Díaz-Zorita 2013: 365), pero no había recibido hasta ahora una explicación satisfactoria. Además, puede tener su correlato cultural en la heterogeneidad arqueológica constatada en el registro funerario respecto a tipo de construcciones, elección de ritual y uso de ajuares mortuorios, un panorama de alta complejidad que, por encima de unos rasgos comunes mínimos, apoyaría la existencia en Valencina de identidades de grupo individualizables (Cruz-Auñón y Mejías 2013).

De confirmarse la propuesta aquí presentada, deberá tenerse en cuenta entonces que la superficie conocida del yacimiento, singular por su enorme tamaño cuando se coteja con la extensión de otros enclaves calcolíticos de la región, se debe en parte a este rasgo especial del sitio como lugar central de una macrocomunidad cohesionada por lazos culturales, políticos y residenciales, y seguramente también genéticos. De hecho, una de las consecuencias que lugares de agregación social y ritual de este tipo han producido a lo largo de la historia es precisamente el nacimiento de fuertes lazos identitarios basados en una koiné cultural y de sangre, que a su vez facilita los contactos entre subunidades con residencia local distinta y los vínculos matrimoniales.

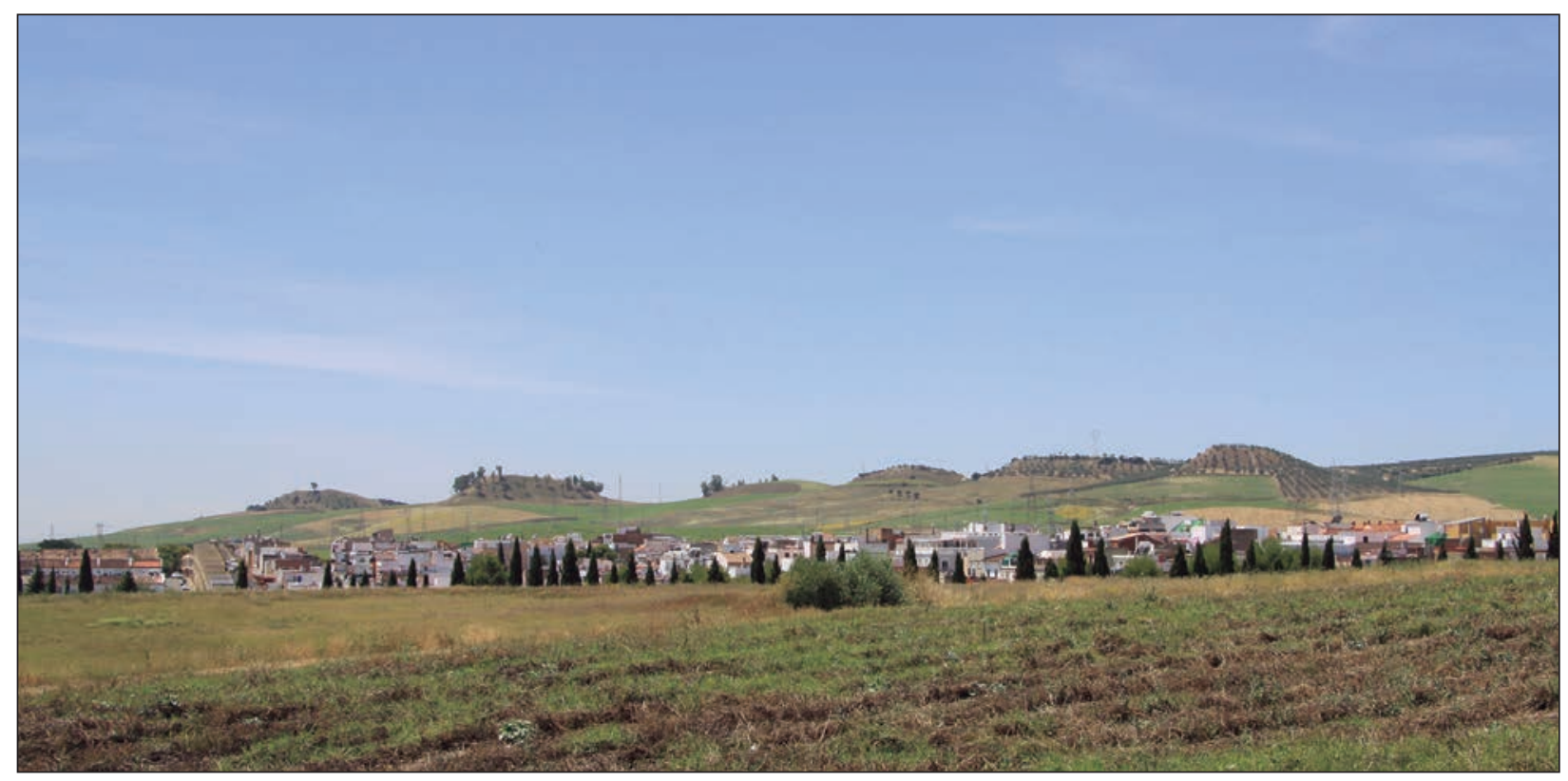

Figura 5. Los cabezos de Valencina constituyen el lugar más elevado de la cornisa oriental del Aljarafe. Su elección como lugar idóneo para la necrópolis comunitaria puede deberse precisamente a su altura sobre el territorio circundante. Panorámica desde el noreste con Santiponce al pie, donde se inicia la Depresión de Gerena. 
Para confirmar este nuevo planteamiento habrá que dar cuenta también de otros muchos rasgos presentes en Valencina que aún no están tratados con la profundidad que hemos dedicado al significado de sus "ídolos" y a la distribución interna de éstos dentro del propio yacimiento. Deberá explicarse algún día, por ejemplo, por qué estas figurillas no se ubicaron siempre en las tumbas propiamente dichas, ocupando a veces oquedades interpretadas como "silos" y/o "pozos". Pero nos parece claro, al menos, que su hallazgo en dichas estructuras subterráneas impide seguir creyendo que sean simple basura escondida bajo la alfombra. La tradición neolítica anterior ya usaba cavidades de este tipo en la misma región que ahora estudiamos, y precisamente para alojar cadáveres o para depositar posibles ofrendas funerarias o restos de banquetes mortuorios. Todo ello en sitios, además, que no eran precisamente poblados porque son sólo esos restos los que conocemos (Escacena 2010: 185-187). Por estas razones, los supuestos silos se interpretan cada vez más como las huellas de reuniones rituales en las que la comida en común pudo representar una de las actividades más importantes realizadas por el grupo. Y de ahí que sus grandes concentraciones en algunos enclaves se hayan valorado como indicadores arqueológicos de sitios de agregación social con alto valor identitario (Mejías et al. 2015: 95).

El diseño de los hipogeos siliformes puede proporcionar otra explicación aún no trabajada y que vendría bien a la hipótesis que aquí defendemos. Su planta y su sección son idénticas a las sepulturas denominadas “cuevas artificiales". Esta modalidad de tumba está constatada de hecho en Valencina (Pajuelo et al. 2013) y se usó profusamente en el mediodía ibérico durante la Edad del Cobre. Se excavaron como sepulturas genuinas y sólo para esta función (Berdichewsky 1964; Rivero 1988). En consecuencia, los "silos" pueden considerarse una variante de las mismas sin entrada lateral, con un diseño tal vez inspirado en la forma de las propias viviendas calcolíticas. De esta manera, se trasladaba a la casa de la muerte el recuerdo de la casa de la vida. Dicha imitación, presente en diversas culturas, exige también su verificación futura, e implicará reconocer que estamos equivocados cuando reconstruimos todas las viviendas de la época sólo como chozas circulares con techumbres vegetales cónicas apoyadas sobre paredes verticales. De hecho, pudieron ser también estructuras cubiertas con cúpulas de barro al estilo de las llamadas "casas colmena" todavía existentes en algunas zonas del Próximo Oriente. Precisamente la bóveda de margas azules que cubría la cámara mayor del hipogeo de Montelirio, paradigma de uno de los enterramientos más singulares de Valencina (Segovia et al. 2016), se convierte, dentro del propio yacimiento, en el primer ejemplo que apuntalaría nuestra interpretación. En la Prehistoria reciente europea existen claras evidencias de que esas "casas de los muertos" se inspiraban a veces en las "casas de los vivos" (fig. 6). Tal propuesta exige repensar los supuestos silos como tumbas, y asumir que se proyectaron con esta finalidad desde el momento de su concepción y construcción. No serían, pues, cavidades excavadas para graneros y luego reutilizadas como sepulturas.

La colocación de los datos funerarios sobre el plano de Valencina contradice la hipótesis tradicional, la que considera a este enclave calcolítico un asentamiento dividido en dos sectores con funciones de hábitat y necrópolis respectivamente. Por una parte, el registro explícitamente funerario no se limita al sector sureste del yacimiento. La presencia de una estructura megalítica levantada con lajas de pizarra en el extremo noroeste, en concreto en el Cerro de la Cabeza, tira por tierra dicha propuesta. Pero a este hecho hay que añadir que algunas de las figurillas adscritas a registros funerarios aparecen en zonas pertenecientes al supuesto sector habitacional; y viceversa, estructuras hipotéticamente defensivas o de almacenamiento de grano se extienden también por áreas mortuorias. Así que la consecuencia más evidente de la nueva hipótesis es la necesidad de interpretar gran parte del registro arqueológico de Valencina desde una perspectiva diferente a la que se ha empleado hasta ahora. Parece demostrado que los fosos no son parte de unas defensas que actuaran a modo de muralla, por lo que podrían recibir un nuevo papel si se consideraran demarcadores de entidades funerarias sociales, familiares o locales, entre otras posibilidades en que se segmentaron los grupos humanos de la época. Lógicamente, esta hipótesis sobre los fosos debería tener en cuenta los diversos recintos que componen algunos de los principales sectores de Valencina donde se conocen con más precisión (Mederos et al. 2016; Schuhmacher et al. 2015), y explicaría por qué no se han comprendido aún su discurrir y su disposición en el conjunto del yacimiento. Es más, daría cuenta de aquellos casos en que sus profundidades se han considerado inadecuadas para darlos por cercas defensivas o por canalizaciones de drenaje. Lo mismo habría que plantear para otras muchas oquedades donde sólo se han constatado vasijas rotas y restos de fauna, siempre interpretadas como simples vertederos para detritos domésticos, cuando conocemos también la existencia en muchas culturas antiguas de depósitos que sólo recibían "despojos" sagrados y la vajilla usada en ceremonias religiosas y banquetes funerarios.

Para esta relectura de Valencina hemos huido intencionadamente de su comparación con otros yacimientos del mediodía ibérico con los que completar la hipótesis o matizarla. Pero somos conscientes de que el modelo aquí defendido no debió ser un unicum. La ausencia de un gran asentamiento fortificado junto a los dólmenes de Antequera puede levantar sospechas de encontrarnos ante un caso semejante. Lo mismo se 

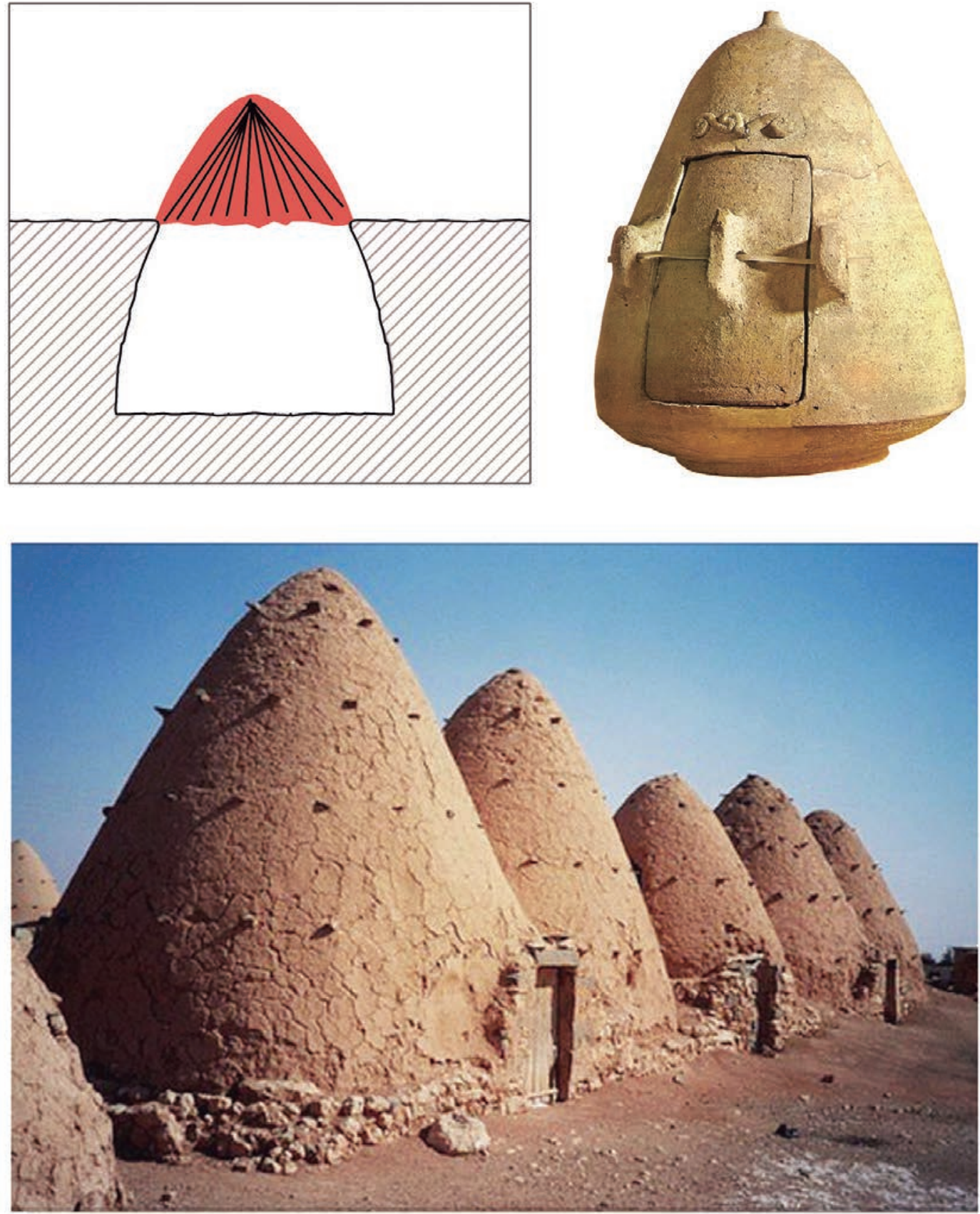

Figura 6. Más que graneros reutilizados como tumbas, los "silos" pudieron ser excavados ex profeso para uso funerario (parte superior izquierda). Propuesta de interpretación como casas del más allá, a imitación de las viviendas de la época, que podrían ser como las casas colmena de barro (parte inferior), con paralelos en las urnas funerarias villanovianas (parte superior derecha).

nos antoja para el recinto de fosos de Perdigões o para el yacimiento extremeño de La Pijotilla. Este tipo de enclaves podría estar dotado de algunas viviendas e incluso de unos cuantos silos auténticos asociados a ellas, ya que una necrópolis comarcal siempre necesitaría servicios litúrgicos y provisiones de diversa índole. Tales demandas contribuirían a dotar al enclave de una indispensable población mínima residente. Por eso no cuenta Valencina con un registro de viviendas tan fecundo como el de Millares pero tampoco debería sorprender el hallazgo de algunas. Cualquier cementerio de cierto tamaño puede incluir dependencias para satisfacer las necesidades subsidiarias de su principal función, la de albergar sepulturas. De esta forma, el "barrio metalúrgico" de Valencina y la "factoría" donde se trabajó el marfil, más que collaciones industriales que suministraban sus manufacturas a un extenso estado calcolítico bajoandaluz, deberíamos conside- 
rarlos simples talleres artesanales que atendían mayormente la demanda local y comarcal. Es más, en nuestra tesis caben otras explicaciones complementarias que den cuenta de los numerosos pozos que albergan "ídolos" en su interior sin contar en cambio con restos humanos. Una de ellas podría ser que estuviéramos ante estructuras que, sin ser la tumba en sí, tenían que ver con ella, cumpliendo por ejemplo el papel de pozo ritual o el de depósito de ofrendas. Se conocen múltiples necrópolis mediterráneas sincrónicas a la de Valencina que cuentan con estas otras estructuras aparte de la cámara mortuoria propiamente dicha. Pero otra hipótesis es que estuviéramos ante la posible huella de cultos funerarios a una divinidad que, en correspondencia con los credos de otras culturas coetáneas, moría y resucitaba. Si tales creencias tuvieran que ver con la parada solsticial por su carácter solar, quedarían explicadas las orientaciones astronómicas de algunos de los recintos de fosos hoy conocidos (Valera 2008), lo que deberá tenerse en cuenta para futuros trabajos en Valencina. De ser así, las figurillas con incisiones en el rostro jugarían el papel de muestras de luto por el fallecimiento anual del dios, y los pozos donde aparecen serían la plasmación concreta de su sepulcro, o tal vez un mero cenotafio. Sin ir más lejos, la diáspora fenicia del primer milenio a.C. extendió por sus territorios coloniales diversas tumbas de Melqart, que jugaban un rol muy importante en la fiesta solsticial de la égersis, cuando se celebraba la resurrección de la divinidad solar al tercer día de su fallecimiento (Escacena 2009).

La nueva interpretación busca, en fin, suscitar un necesario debate acerca del papel histórico de la Valencina calcolítica, todo ello en función del peculiar registro arqueológico que muestra el propio yacimiento y su territorio circundante. No persigue tanto desmontar anteriores explicaciones -esto podría ser una consecuencia, no un objetivo- cuanto señalar que existen otras hipótesis posibles con las que operar. En cualquier caso, para comprender adecuadamente la nueva propuesta es necesario olvidar la arraigada tradición historiográfica que ha dividido el yacimiento en dos realidades dicotómicas: poblado y necrópolis. Al difuminar la supuesta frontera entre esos dos ámbitos, la distribución de los hallazgos permite construir interpretaciones distintas de la habitual. Si la nuestra recibiera cada vez más apoyo de los datos, habría que deducir que el modelo propuesto de manera implícita, que podríamos denominar mosaico de distritos funerarios, constituiría una de las pautas posibles de organización territorial del Calcolítico en el cuadrante suroccidental de la península ibérica.

\section{Agradecimientos}

El presente artículo se ha elaborado en el marco del Grupo de Investigación Tellus (HUM-949 del Plan Andaluz de Investigación, Desarrollo e Innovación) y del Proyecto HAR2017-89004-P.
Conocemos el yacimiento de Cañada Fría -o El Despiste-, al oeste de La Puebla del Río, por las prospecciones parcialmente inéditas de Jesús de la Ascensión Salas Álvarez y Manuel Mesa Romero. Los correspondientes al término de Olivares han sido documentados por Urbano López Ruiz, quien amablemente ha puesto los datos a nuestra disposición para su futura publicación. Mark Hunt Ortiz, del Departamento de Prehistoria y Arqueología de la Universidad de Sevilla, nos ha facilitado algunos datos inéditos sobre hallazgos calcolíticos de Aznalcóllar. Finalmente, Pedro Rodríguez Cuevas nos ha comunicado la excavación por su parte de un poblado calcolítico en El Zaudín (Tomares). Queremos expresar nuestro agradecimiento a todos estos investigadores.

\section{BIBLIOGRAFÍA}

Alcalde, D.; Buxó, R (1992): “Experimentació d'emmagatzematge i explotació de Triticum dicoccum Sch. a la Vall del Llierca (La Garrotas)". Cypsela, 9: 87-94.

Almagro, M.; Arribas, A. (1963): El poblado y la necrópolis megalíticos de Los Millares (Santa Fe Mondújar, Almería). Bibliotheca Praehistorica Hispana III. CSIC. Madrid.

Almagro, M.J. (1973): Los ídolos del Bronce I Hispánico. Bibliotheca Praehistorica Hispana XII. Consejo Superior de Investigaciones Científicas. Madrid.

Arribas, A.; Molina, F.; Saez, L.; De la Torre, F.; Aguayo, P.; Bravo, A.; Suárez, A. (1983): "Excavaciones en Los Millares (Santa Fe de Mondújar, Almería). Campañas de 1982 y 1983". Cuadernos de Prehistoria de la Universidad de Granada, 8: 123-147.

Arteaga, O.; Cruz-Auñón, R. (1995): “Una valoración del patrimonio histórico en el campo de silos de la finca El Cuervo-RTVA (Valencina de la Concepción, Sevilla). Excavación de urgencia de 1995".Anuario Arqueológico de Andalucía 1995. III, Actividades de Urgencia: 608-616. Junta de Andalucía. Sevilla.

Arteaga, O.; Schulz, H.D.; Roos, A.M. (1995): “El problema del 'Lacus Ligustinus'. Investigaciones geoarqueológicas en torno a las Marismas del Bajo Guadalquivir". Tartessos 25 años después, 19681993, Jerez de la Frontera: 99-135. Ayuntamiento de Jerez de la Frontera. Jerez de la Frontera.

Benítez de Lugo, L.; Mejías, M. (2015): “La prehistórica Cultura de las Motillas: nuevas propuestas para un viejo problema". Veleia, 32: 111-124. https://doi.org/10.1387/veleia.14981

Berdichewsky, B. (1964): Los enterramientos en cuevas artificiales del Bronce I Hispánico. Bibliotheca Praehistorica Hispana VI. CSIC. Madrid. 
Bueno, P.; De Balbín, R.; Barroso Bermejo, R.; Carrera, F.; Hunt, M. (2016): "El arte y la plástica en el tholos de Montelirio". Á. Fernández Flores et al. (eds.), Montelirio. Un gran monumento megalítico de la Edad del Cobre. Junta de Andalucía. Sevilla: 365-405.

Buxó, R. (1997): Arqueología de las plantas. La explotación económica de las semillas y los frutos en el marco mediterráneo de la península ibérica. Crítica. Barcelona.

Cáceres, L.M.; Rodríguez Vidal, J.: Muñiz, F.; Donaire, T. (2013): "Rasgos bioerosivos en rocas de la Pastora (Valencina de la Concepción, Sevilla): implicaciones cronológicas y paleoambientales". L. García Sanjuán et al. (eds.), El asentamiento prehistórico de Valencina de la Concepción (Sevilla): Investigación y tutela en el 150 aniversario del descubrimiento de La Pastora. Universidad de Sevilla. Sevilla: 219-232.

Carriazo, J. de M. (1966): Memoria de los trabajos de excavación y hallazgos arqueológicos realizados en la zona de Sevilla durante el año 1965. Noticiario Arqueológico Hispánico VIII-IX (1-3), 1964-65. Ministerio de Educación y Ciencia. Madrid: 301-312.

Carriazo, J. de M. (1973): Tartesos y el Carambolo. Investigaciones arqueológicas sobre la Protohistoria de la Baja Andalucía. Ministerio de Educación y Ciencia. Madrid.

Collantes de Terán, F. (1969): "El dolmen de Matarrubilla". Tartessos y sus problemas. V Symposium Internacional de Prehistoria Peninsular. Universidad de Barcelona. Barcelona: 47-61.

Conlin, E. (2017): "Rituales y elementos simbólicos del IV al III milenio a.C. Carmona". M. González Jiménez y A. Caballos (eds.), Religión y espiritualidad en Carmona. De la Prehistoria a los tiempos contemporáneos. Actas del X Congreso de Historia de Carmona. Universidad de Sevilla. Sevilla: 21-48.

Cruz-Auñón, R.; Mejías, J.C. (2013): “Diversidad de prácticas funerarias e identidades en el asentamiento de Valencina de la Concepción (Sevilla)". L. García Sanjuán et al. (eds.), El asentamiento prehistórico de Valencina de la Concepción (Sevilla): Investigación y tutela en el 150 aniversario del descubrimiento de La Pastora. Universidad de Sevilla. Sevilla: 175-199.

Del Olmo, G. (1995): "Mitología y religión de Siria en el II milenio a.C. (1500-1200)”. G. del Olmo (ed.), Mitología y religión del Oriente Antiguo. II/2, Semitas occidentales (Emar, Ugarit, hebreos, fenicios, arameos, árabes). Ausa. Sabadell: 45-222.

Díaz-Zorita, M. (2013): "Bioarqueología de las prácticas funerarias del yacimiento de la Edad del Cobre de Valencina de la Concepción-Castilleja de Guzmán (Sevilla): revisión de las investigaciones". L. García Sanjuán et al. (eds.), El asentamiento prehistórico de Valencina de la Concepción (Sevilla): Investigación y tutela en el 150 aniversario del descubrimiento de La Pastora. Universidad de Sevilla. Sevilla: 359-367.

Emslie, S.; Mckenzie, A.C.; Shaller, E. (2016): "Análisis de mercurio de los restos humanos del tholos de Montelirio". Á. Fernández Flores et al. (eds.), Montelirio. Un gran monumento megalítico de la Edad del Cobre: 449-454). Junta de Andalucía. Sevilla.

Escacena, J.L. (2007): "Ilipa en el contexto de la Prehistoria Reciente y Protohistoria del paleoestuario del Guadalquivir". E. Ferrer et al. (eds.), Ilipa Antiqva. De la Prehistoria a la Época Romana. Ayuntamiento de Alcalá del Río - Cajasol. Sevilla: 13-28.

Escacena, J.L. (2009): "La égersis de Melqart. Hipótesis sobre una teología solar cananea". Complutum, 20 (2): 95-120.

Escacena, J.L. (2010): "La salina prehistórica de La Marismilla y la ocupación neolítica de la paleodesembocadura del Guadalquivir". J.L. Escacena (coord.), La Puebla del Río. Miscelánea histórica. Universidad de Sevilla - Diputación de Sevilla, Sevilla: 167-189.

Escacena, J.L. (2016): "Rasguños faciales por luto, o sobre el «tatuaje» de los idolillos calcolíticos hispanos". J. García Sánchez et al., Navigare necesse est. Estudios en homenaje a José María Luzón Nogué. Universidad Complutense. Madrid: 99116.

Escacena, J.L.; De Frutos, G. (1981-82): "Enterramientos de la Edad del Bronce del Cerro del Berrueco (Medina Sidonia, Cádiz)". Pyrenae, 17-18: 165-190.

Escacena, J.L.; Gómez Peña, Á., (2015): “Símbolos de duelo. Sobre el mensaje de las máscaras gesticulantes fenicias". Madrider Mitteilungen, 56: 62-87.

Escacena, J.L.; Izquierdo, R. (1999): "Proyecto Estuario. Intervención Arqueológica de 1994". Anuario Arqueológico de Andalucía / 1994. II, Actividades Sistemáticas. Junta de Andalucía. Sevilla: 161-166.

Escacena, J.L.; Tabales, M.A. (2015): “Datos prehistóricos y primera ocupación”. M.A. Tabales, Excavaciones arqueológicas en el Patio de Banderas, Alcázar de Sevilla. Memoria de Investigación 2009-2014. Real Alcázar de Sevilla. Sevilla: 52-67.

Fernández Flores, Á.; Rodríguez Azogue, A. (2010): "El Carambolo, secuencia cronocultural del yacimiento. Síntesis de las intervenciones 2002-2005". 
M. L. De la Bandera y E. Ferrer (coord.), El Carambolo. 50 años de un tesoro. Universidad de Sevilla. Sevilla: 203-270.

Fernández Flores, Á; García Sanjuán, L.; Díaz-Zorita, M. (eds.) (2016): Montelirio. Un gran monumento megalítico de la Edad del Cobre. Junta de Andalucía. Sevilla.

Fernández Gómez, F.; Alonso de la Sierra, J. (1985): Un fondo de cabaña campaniforme en la Universidad Laboral de Sevilla. Noticiario Arqueológico Hispánico 22. Ministerio de Cultura. Madrid: 7-26.

Fernández Gómez, F.; Guerrero, L.J.; Ventura, J.J.; De la Hoz, A.; De la Sierra, J.A.; Alcázar, J.; Suárez, A. (1997): Orippo en la Antigüedad. Las excavaciones arqueológicas de 1979 a 1983. Ayuntamiento de Dos Hermanas. Dos Hermanas.

Fernández Gómez, F.; Oliva, D. (1985): Excavaciones en el yacimiento calcolítico de Valencina de la Concepción (Sevilla). El corte C («La Perrera»). Noticiario Arqueológico Hispánico 25. Ministerio de Cultura. Madrid: 7-131.

Fernández Gómez, F.; Ruiz Mata, D.; De Sancha, S. (1976): "Los enterramientos en cistas del cortijo de Chichina (Sanlúcar la Mayor, Sevilla)".Trabajos de Prehistoria, 33: 351-386.

Fernández Gómez, F.; Oliva, D. (1980): “Los ídolos calcolíticos del Cerro de la Cabeza (Valencina de la Concepción, Sevilla)". Madrider Mitteilungen, 21: $20-44$.

Frazer, J.G. (1981) [1907-1918]: El folklore en el Antiguo Testamento. Fondo de Cultura Económica. México D.F.

García Rivero, D.; Escacena, J.L. (2015): “Del Calcolítico al Bronce Antiguo en el Guadalquivir inferior. El Cerro de San Juan (Coria del Río, Sevilla) y el "modelo de reemplazo". Zephyrus, 76: 15-38. https://doi.org/10.14201/zephyrus 2015761538

García Rivero, D.; O’Brian, M.J. (2014): "Phylogenetic analysis shows that neolithic slate plaques from the southwestern Iberian peninsula are not genealogical recording systems". PLOS ONE, 9 (2): e88296. https://doi.org/10.1371/journal.pone .0088296

García Sanjuán, L. (2013): "El asentamiento de la Edad del Cobre de Valencina de la Concepción: estado actual de la investigación, debates y perspectivas". L. García Sanjuán et al. (eds.), El asentamiento prehistórico de Valencina de la Concepción (Sevilla): Investigación y tutela en el 150 aniversario del descubrimiento de La Pastora. Universidad de Sevilla. Sevilla: 21-59.

García Sanjuán, L.; Lozano, J.A.; Sánchez Liranzo, O.; Gibaja, J.; Aranda, V. (2016): "La industria lítica del tholos de Montelirio". Á. Fernández Flores et al. (eds.), Montelirio. Un gran monumento megalítico de la Edad del Cobre. Junta de Andalucía. Sevilla: 203-244.

García Sanjuán, L.; Murillo-Barroso, M. (2013): "Social complexity in Copper Age Southern Iberia (ca. 3200-2200 Cal b.c.)". M. Cruz et al. (eds.), The Prehistory of Iberia. Debating early social stratification and the state. Routledge. Nueva York: 119-140.

García Sanjuán, L.; Scarre, Ch.; Wheatley, D.W. (2017): "The mega-site of Valencina de la Concepción (Seville, Spain): debating settlement form, monumentality and aggregation in southern Iberian Copper Age societies". Journal of World Prehistory. https://doi.org/10.1007/s10963-0179107-6

García Sanjuán, L.; Vargas, J.M.; Cáceres, L.M.; Costa, M.E.; Díaz-Guardamino, M.; Díaz-Zorita, M.; Fernández, Á.; Hurtado, V.; López, P.; Méndez, E.; Pajuelo, A.; Rodríguez, J.; Wheatley, D.; Bronk, C.; Delgado-Huertas, A.; Dunbar, E.; Mora, A.; Bayliss, A.; Beavan, N.; Hamilton, D.; Whittle, A. (2018): “Assembling the dead, gathering the living: Radiocarbon dating and Bayesian modelling for Copper Age Valencina de la Concepción (Seville, Spain)". Journal of World Prehistory, 31: 179-313. https://doi.org/10.1007/s 10963-018-9114-2

García Sanz, C.; Fernández Jurado, J. (1999): La época calcolítica de San Bartolomé de Almonte, monográfico de Huelva Arqueológica, 15. Diputación de Huelva. Huelva.

Gavilán, B. (2007): "El yacimiento calcolítico de La Angorrilla: ¿Los orígenes del poblamiento estable?". E. Ferrer et al. (eds.), Ilipa Antiqva. De la Prehistoria a la Época Romana. Ayuntamiento de Alcalá del Río - Cajasol. Sevilla: 55-68.

Gavilán, B.; Escacena, J.L. (2009): “Acerca del primer Neolítico de Andalucía occidental. Los tramos medio y bajo de la cuenca del Guadalquivir". Mainake, XXXI: 311-351.

Guisado, F.; Garrido, P.; Costa, M.E. (2010): Catálogos de Bienes Protegidos del PGOU de Gerena. Tomo III. Ayuntamiento de Gerena Diputación de Sevilla. Inédito, disponible en http://3web.dipusevilla.es/planeamiento/gerena10/045PGai.htm.

Hunt, M. A. (2012): Intervenciones arqueológicas en el área del proyecto minero Cobre Las Cruces (1996-2011): de la Prehistoria a la Época Contemporánea. Fundación Cobre Las Cruces. Sevilla.

Hunt, M.A. (2000): “Intervención arqueológica en el coto minero de Aznalcóllar (Sevilla): el yacimiento calcolítico de Los Páramos y la necrópolis de 
cistas de Las Mesas". Anuario Arqueológico de Andalucía / 2000. III, Actividades de Urgencia, vol. 2. Junta de Andalucía. Sevilla: 1196-1202.

Hunt, M.A.; Vázquez, J.; Garrido, P. (2017): Aznalcóllar, Sevilla. Carta Arqueológica Municipal. Junta de Andalucía - Ayuntamiento de Aznalcóllar. Sevilla.

Hurtado, V. (2004): "El asentamiento fortificado de San Blas (Cheles, Badajoz). III milenio AC". Trabajos de Prehistoria, 61 (1): 141-155. https://doi.org/10.3989/tp.2004.v61.i1.33

Hurtado, V. (2013): "Los ídolos del asentamiento de Valencina de la Concepción (Sevilla): una revisión". L. García Sanjuán et al. (ed.), El asentamiento prehistórico de Valencina de la Concepción (Sevilla): Investigación y tutela en el 150 aniversario del descubrimiento de La Pastora. Universidad de Sevilla. Sevilla: 311-327.

Hurtado, V.; Amores, F. (1984): "El tholos de Las Canteras y los enterramientos del Bronce en la necrópolis de El Gandul (Alcalá de Guadaira, Sevilla)".Cuadernos de Prehistoria de la Universidad de Granada, 9: 147-174.

IAPH (2000): Megalitos de la provincia de Sevilla. PH Ediciones Multimedia 3. Junta de Andalucía. Sevilla.

Jiménez, V.; Márquez, J.E. (2006): “Aquí no hay quien viva". Sobre las casas-pozo en la prehistoria de Andalucía durante el IV y el III milenios AC". Spal, 15: 39-49. https://doi.org/10.12795/spal. 2006.i15.03

Lara, D.A.; Barragán, D.; Garrido, M. (2004): “El asentamiento calcolítico del Parque de Miraflores (Sevilla): resultados preliminares". Spal, 13: 245 255. https://doi.org/10.12795/spal.2004.i13.09

Lillios, K. (2008): Heraldry for the dead. Memory, identity, and the engraved stone plaques of Neolithic Iberia. University of Texas Press. Austin.

Márquez, J.E.; Jiménez, V. (2010): Recintos de fosos. Genealogía y significado de una tradición en la Prehistoria del suroeste de la península ibérica ( $I V$ III milenios $A C$ ). Universidad de Málaga. Málaga.

Martín de la Cruz, J.C. (1985): Papa Uvas I. Aljaraque, Huelva. Campañas de 1976 a 1979. Excavaciones Arqueológicas en España 136. Ministerio de Cultura. Madrid.

Mederos, A.; Vargas, J.M.; Schuhmacher, Th.X.; Falkenstein, F.; Link, T. (2016): "Prospecciones arqueológicas y geomagnéticas en los cerros de la Cabeza y del Mármol, sector norte del poblado calcolítico de Valencina (Sevilla). Campaña de 2014". Spal, 25: 11-42. https://doi.org/10.12795/spal. $2016 \mathrm{i} 25.01$
Mejías, J.C. (2011): El asentamiento de Valencina en el III milenio a.n.e. Sistema de información geográfica y análisis espacial de un recinto de fosos. Inédito, disponible en:

https://www.academia.edu/6432717/E1_asentamiento_de_Valencina_en_el_III_milenio_a.n.e._S istema_de_Informaci\%C3\%B3n_Geogr\%C3\%A1f ica_y_An\%C3\%A1lisis_Espacial_de_un_recinto_de_fosos.

Mejías, M.; Benítez de Lugo, L.; López, J.A.; Esteban, C. (eds.) (2015): Arqueología, hidrogeología y medio ambiente en la Edad del Bronce de La Mancha. La Cultura de las Motillas. Instituto Geológico y Minero de España. Madrid.

Murillo, T. (2013): "La manufactura de artefactos líticos de la Edad del Cobre en el territorio de Valencina de la Concepción (Sevilla)". L. García Sanjuán et al. (eds.), El asentamiento prehistórico de Valencina de la Concepción (Sevilla): Investigación y tutela en el 150 aniversario del descubrimiento de La Pastora. Universidad de Sevilla, Sevilla: 469-484.

Murillo-Barroso, M. (2016): "El oro del tholos de Montelirio en el contexto de la tecnología áurea de Valencina". Á. Fernández Flores et al. (eds.), Montelirio. Un gran monumento megalítico de la Edad del Cobre. Junta de Andalucía. Sevilla: 285-309.

Murillo-Barroso, M.; Costa, M.E.; Díaz-Guardamino, M.; García Sanjuán, L.; Mora, C. (2015): “A reappraisal of Iberian Copper Age goldwork: craftmanship, symbolism and art in a non-funerary gold sheet from Valencina de la Concepción". Cambridge Archaeological Journal, 25 (3): 565-596. https://doi.org/10.1017/S0959774314001127

Nocete, F. (2001): Tercer milenio antes de nuestra era. Relaciones y contradicciones centro/periferia en el Valle del Guadalquivir. Bellaterra. Barcelona.

Nocete, F.; Queipo, G.; Sáez, R.; Nieto, J.M.; Inácio, N.; Bayona, M.R.; Peramo, A.; Vargas, J.M.; CruzAuñón, R.; Gil-Ibarguchi, J.I.; Santos, F. (2008): "El barrio metalúrgico de Valencina de la Concepción (Sevilla, España): la industria especializada del cobre en un centro político del Valle del Guadalquivir durante el Tercer Milenio a.n.e. (2750-2500 a.n.e.)". Journal of Archaeological Science, 35: 717-732. https://doi.org/10.1016/j.jas. 2007.05.019

Odriozola, C.: Vargas, J.M.; Martínez-Blanes, J.M.; García Sanjuán, L. (2016): "El hacha pulimentada de jade de la Colección Tubino (Museo Municipal, Valencina de la Concepción, Sevilla)". Spal, 25: 211-227. https://doi.org/10.12795/spal.2016i25.08

Pajuelo, A.; López, P.M.; Cruz-Auñón, R.; MejíasGarcía, J.C. (2013): "Las cuevas artificiales de Valencina. Análisis y propuestas de la distribución 
espacial a escala regional". J. Jiménez Ávila et al. (coords.), VI Encuentro de Arqueología del Suroeste Peninsular. Ayuntamiento de Villafranca de los Barros: 285-318.

Pellicer, M. (1986): "El Cobre y el Bronce Pleno en Andalucía Occidental". Homenaje a Luis Siret (1934-1984). Junta de Andalucía. Sevilla: 245-250.

Rendón, A. (1994): Aznalcóllar. Aproximación histórico cultural. Inédito, disponible en http://www .aznalcollar.es/opencms/export/sites/de fault/aznalcollar/galeriaFicheros/Aznalcollar.Acer camiento_Historico_Cultural.pdf.

Reynolds, P.J. (1988): Arqueología experimental: una perspectiva de futur. Eumo. Vic.

Rivero, E. (1988): Análisis de las cuevas artificiales en Andalucía y Portugal. Universidad de Sevilla. Sevilla.

Rodríguez de Guzmán, S.; Cáceres, P. (1988): "Informe de la prospección arqueológica superficial del término municipal de Aznalcázar (Sevilla)". Anuario Arqueológico de Andalucía / 1988. III, Actividades de Urgencia. Junta de Andalucía. Sevilla: 377-381.

Ruiz Mata, D. (1975): “Cerámicas del Bronce del poblado de Valencina de la Concepción (Sevilla): los platos". Cuadernos de Prehistoria y Arqueología de la Universidad Autónoma de Madrid, 2: 123-149. https://doi.org/10.15366/ cupauam1975.2.010

Ruiz Mata, D. (1978-79): "Nuevos yacimientos campaniformes en la provincia de Sevilla". Cuadernos de Prehistoria y Arqueología de la Universidad Autónoma de Madrid, 5-6: 41-57. http://hdl.handle.net/10486/556

Ruiz Mata, D. (1983): "El yacimiento de la Edad del Bronce de Valencina de la Concepción (Sevilla) en el marco cultural del Bajo Guadalquivir". Actas del
I Congreso de Historia de Andalucía. Prehistoria y Arqueología. Monte de Piedad y Caja de Ahorros de Córdoba. Córdoba: 183-208.

Ruiz-Gálvez, M. (1992): “Orientaciones teóricas sobre intercambio y comercio en Prehistoria”. Gala, 1: 87-101.

Schuhmacher, T.; Falkenstein, F.; Link, Th.; Mederos, A.; Vargas, J.M. (2015): "Archäologische und geophysikalische Prospektionen im Nordbereich der chalkolithischen Siedlung von Valencina de la Concepción bei Sevilla (Andalusien) im Jahr 2014". Madrider Mitteilungen, 56: 1-39.

Schuhmacher, Th.X. (2016): Elfenbeinstudien Faszikel 3: Elefanten und Elfenbein auf der Iberischen Halbinsel und in Nordwestafrika. Interdisziplinäre Studien zu Austauschsystemen im 3. Und der ersten Hälfte des 2. Jts. V. Chr. Iberia Archaeologica 16-3. Wasmuth. Berlin.

Segovia, M.L.; Legaz, S.; Segovia, F.J. (2016): "Análisis estructural de la cúpula de la cámara grande de Montelirio”. Á. Fernández Flores et al. (eds.), Montelirio. Un gran monumento megalítico de la Edad del Cobre. Junta de Andalucía. Sevilla: 155-162.

Serna, M.R. (1989): "El vaso campaniforme en el Valle del Guadalquivir". M.E. Aubet (coord.), Tartessos. Arqueología protohistórica del Bajo Guadalquivir. Ausa. Sabadell: 47-84.

Valera, A.C. (2008): "Mapeando o cosmos. Uma abordagem cognitiva aos recintos da Pré-História recente". ERA Arqueologia, 8: 112-127.

Zafra, N.; Hornos, F.; Castro, M. (1999): "Una macroaldea en el origen del modo de vida campesino: Marroquíes Bajos (Jaén) c. 2500-2000 cal. ANE”. Trabajos de Prehistoria, 56 (1): 77-102. https://doi.org/10.3989/tp.1999.v56.i1.291 